\title{
Serials Spoken Here : Reports of Conferences, Institutes, and Seminars
}

\author{
Kurt Blythe, Maria Aghazarian, Anjana H. Bhatt, Rachel Becker, Gordon \\ Coleman, Leigh Ann DePope, Kimberly DeRosa, Dianne Ford, Molly Galey, \\ John Kimbrough, Laura Kohl, Camelia Naranch, Jharina Pascual, Martin \\ Patrick, Emily Ray, Kristin Rogers, Katherine H. Ryner, Tracie Seurer \& \\ Breanna Webb
}

To cite this article: Kurt Blythe , Maria Aghazarian, Anjana H. Bhatt, Rachel Becker, Gordon Coleman, Leigh Ann DePope, Kimberly DeRosa, Dianne Ford, Molly Galey, John Kimbrough, Laura Kohl, Camelia Naranch, Jharina Pascual, Martin Patrick, Emily Ray, Kristin Rogers, Katherine H. Ryner, Tracie Seurer \& Breanna Webb (2017): Serials Spoken Here : Reports of Conferences, Institutes, and Seminars, Serials Review, DOI: 10.1080/00987913.2017.1282289

To link to this article: http://dx.doi.org/10.1080/00987913.2017.1282289

Accepted author version posted online: 07

Mar 2017.

Submit your article to this journal $₫$

View related articles ¿

View Crossmark data $₫$ 


\section{ACCEPTED MANUSCRIPT}

Serials Spoken Here

Reports of Conferences, Institutes, and Seminars

Contributors

Maria Aghazarian, Anjana H. Bhatt, Rachel Becker, Gordon Coleman, Leigh Ann DePope, Kimberly DeRosa, Dianne Ford, Molly Galey, John Kimbrough, Laura Kohl, Camelia Naranch, Jharina Pascual, Martin Patrick, Emily Ray, Kristin Rogers, Katherine H. Ryner, Tracie Seurer, and Breanna Webb

Kurt Blythe, Column Editor

Serials Access Librarian, Davis Library, University of North Carolina at Chapel Hill, Chapel

Hill, NC 27514,USA; email: kcblythe@email.unc.edu

Abstract

This quarter's column offers a report from the Acquisitions Institute at Timberline Lodge, held May 14-17 in Timberline Lodge, OR, and also provides coverage of multiple sessions from the Kraemer Copyright Conference, held June 6-7 in Colorado Springs, CO. Some reports are collected, as well, from the NASIG Annual Conference, held June 9-12 in Albuquerque, NM, and the American Library Association (ALA) Annual Conference, held June 23-28 in Orlando, FL. Lastly, there is a report from the International Federation of Library Associations and Institutions (IFLA) World Library and Information Congress, held August 13-19, 2016 in Columbus, OH. Topics covered include open access, linked data, copyright, text mining, eresource management, and digitization.

Keywords: open access; linked data; copyright; text mining; eresource management; digitization 


\section{ACCEPTED MANUSCRIPT}

\section{Acquisitions Institute}

Katherine H. Ryner

Associate Director of the Library \& Head of Collections Support Services, St. Mary's College of Maryland, St. Mary’s City, MD, 20686, USA; email: khryner@smcm.edu

The 2016 Acquisitions Institute at Timberline Lodge was held on May 14-17 on Mt. Hood in

Oregon. Serials-related conference sessions were held on subscription agents and on re-thinking serials budgets.

Taking aim at an old problem: Serials management at the University of Oregon Libraries, aka journal management in the cross-hairs

Mark Watson (associate dean for research services, University of Oregon) discussed how his library adopted a new approach to managing scholarly journal and database subscriptions. Watson first explained that his institution has suffered constant rounds of budget cuts since the 1960s: the university has reduced recurring expenditures every five years on average for the past fifty years. He reminded the audience of some of the many factors that contribute to the current scholarly publishing climate, including increases in journal prices and decreases in library budgets. Scholarly journals and databases (SJ\&Ds) are meant to run indefinitely, and scholars come to depend on them; as an SJ\&D builds a reputation and rises to prominence, faculty come to depend on it as a venue in which to publish their scholarship as part of the promotion-andtenure process. Faculty sign away their copyright to publishers and then publishers in turn sell journal subscriptions back to university libraries. This structural imbalance is an ongoing 


\section{ACCEPTED MANUSCRIPT}

problem, and the solution will require changing how the academy disseminates and rewards new knowledge.

The escalation in subscription costs and subsequent pressures on library budgets has turned libraries into, as Watson put it, "perpetual beggars of their administrations". He asked, "Can we break the cycle of beg -- spend -- cut?" He then proceeded to explain how his library implemented a two-year plan designed to reduce the need to beg the university for ever-larger sums of money each year just to cover inflation.

Recognizing the need to widen the conversation about the scholarly publishing cycle, Watson and his colleagues designed their plan to increase the involvement of subject librarians and their faculty. The main element of the new model is that they now treat funds devoted to subjectspecific SJ\&Ds as fixed, rather than ongoing, allocations. There are no more separate pots of money to buy new books versus new serials or databases. In other words, a subject-specific request is now allocated out of a single subject-specific discretionary fund. If a new purchase request requires an ongoing commitment, the subject librarian must agree to have the money moved from their discretionary fund to a recurring-obligation fund. The reverse is true when a recurring obligation is canceled. Inflationary increases are covered through cancellations or by moving discretionary funds; that choice is left to the subject specialist. In this way, subject specialists and the faculty in their areas are assuming more responsibility for managing inflationary increases.

Other elements of the new model include addressing high-inflation titles on a case-by-case basis, providing usage data to subject librarians in a timely fashion, and keeping an eye out for SJ\&Ds 


\section{ACCEPTED MANUSCRIPT}

with price increases that are higher than projected. Multi-year package deals are treated separately.

In conclusion, Watson related that the coming fiscal year presents a worst-case scenario for his library: unlike past years, they are not receiving any funds to cover inflation. Discretionary funds in some subject areas have already run dry; for example, the subject librarian for business has already moved all of her discretionary money into the recurring-obligation fund. He does not know how this major fund restructuring will work in the long run. The hope is that librarians and faculty will work together to solve problems rather than the library trying to hide the problem until forced to do disruptive cancellations.

\section{Kraemer Copyright Conference}

Kimberly DeRosa

Serials Specialist, University of Colorado Denver, Denver, CO 80204, USA; email: kimberly.derosa@ucdenver.edu

The 2016 Kraemer Copyright Conference was held June 6-7, 2016, at the University of Colorado Colorado Springs, Colorado. Over the course of the two-day conference speakers presented on copyright law and its effects on libraries.

Past, present, and future of mass digitization

Kevin Smith (dean of libraries, University of Kansas) presented "Past, Present, and Future of Mass Digitization.” Before his position as dean at the University of Kansas Libraries, Smith worked as the director of copyright and scholarly communications at Duke University Libraries. 


\section{ACCEPTED MANUSCRIPT}

Smith's presentation gave insight into the beginnings of mass digitization, court cases, examples of mass digitization throughout history, and the possible future directions of mass digitization.

Per Smith, mass digitization began during the time of World War II with Vannevar Bush who was the head of the Office of Scientific Research \& Development. During this period, mass digitization was idealized to be available on "Memex," which was based off of microfilm. The main question about "mass digitization" during this period was the effect knowledge would have on the world if it was shared more broadly.

After this brief history, Smith dove into several mass digitization projects and the different aspects of each. He began with Project Gutenberg, which started in 1971 and focused on access for the public domain. Project Gutenberg, Smith explains, makes no copyright claim over created digital versions, but there are some noncommercial restrictions enacted if trademark is used.

Next was the Library of Congress \& Ameritech Corp digitization project that began in 1990 called "American Memory." Most of these works are available in the public domain, but Smith also explained that fair use was used during this digitization project. Additionally, the Library of Congress will not grant or deny copyright permissions to anyone for the items in this project.

Started after the "American Memory" digitization project, Duke University began the Duke Digital Scriptorium in 1996 that digitized items in the university collections. This included Greek papyri, Civil War papers, nineteenth-century sheet music and different American advertising campaigns that were pre-1923. All of the works Duke digitized are in the public domain. Additionally, Duke invested a lot of work in the metadata for these items. 


\section{ACCEPTED MANUSCRIPT}

One of the largest mass digitization projects Smith presented on is Google Books. This project began in 2004, partnering Google with five different libraries. It is a high-speed digitization project with a focus on quantity instead of quality. Because of the project's violation of copyright, lawsuits ensued shortly after the project began. A settlement was proposed in 2008, but took three years for a judge to reject it. Ultimately, it was not until 2016 that the Google Books case was settled. The court ruled in favor of Google and the five libraries citing fair use. Another appeal of the case was made to the second circuit court, which was also ruled in favor of Google citing fair use. Having the final say, the Supreme Court rejected the final appeal, thus ending any further litigation.

Towards the end of the presentation Smith discussed section 108 of copyright law, fair use, the current legal landscape, and future possible directions for libraries and copyright. Ultimately, with possible upcoming revisions to section 108, libraries do not have a clear answer on how they will be affected. The courts decide case by case if libraries or other educational entities violate copyright law. Therefore, keeping current with copyright news and reviewing the four factors (purpose and character of use, nature of the work, amount and substantiality of the portion used, and effect on the potential market) of fair use are helpful tools when it comes to questions about violating copyright.

Molly Galey

Acquisitions Assistant, Auraria Library, Denver, CO 80204, USA; email: galey@colorado.edu Copyright, libraries, and the ethics imperative 


\section{ACCEPTED MANUSCRIPT}

Kenneth D. Crews hosted a forum on the ethical imperatives of copyright librarians, addressing dually the responsibility to library patrons and to the law. Crews focused mainly on the ways librarians, particularly those with a title such as "copyright librarian" or "copyright specialist," should and should not respond to questions about copyright law.

The key topic of the session was whether librarians should provide law-related information with regard to copyright. Crews asked how many people in attendance had a law degree, and about four or five raised their hands out of about thirty or forty attendees. Crews was not surprised, implying that this outcome was representative of a majority of copyright librarians, and stressing that it is important for those without a law degree to know how far to go in handling legal questions. Crews laid out several scenarios for discussion, one of which dealt with Section 108 of the U.S. Copyright Act. Crews observed that there are ethical responsibilities for determining whether to field the question yourself or refer the question to legal counsel. Here, Crews made his main point of the lecture: the copyright-wise librarian must ask herself if she should be the one to answer a patron or coworker's copyright question.

Crews explained that copyright decisions are a form of legal advice, and only licensed attorneys are legally allowed to give advice of this nature. However, in the instance of a copyright decision a copyright librarian can legally give themselves advice--essentially making a legal interpretation - and convey that thought to another. After all, in the United States one can serve as one's own legal representation in other contexts. This seems to be one distinction under which a copyright librarian has the right to advise others. Crews then laid out several approaches to handling various forms of copyright queries. 


\section{ACCEPTED MANUSCRIPT}

The easiest question the copyright librarian faces is, "how do I get copyright?" The answer is probably the simplest and most appreciated answer one can give: in most cases, the questioner already has copyright on his or her work, simply by virtue of creating it. However, Crews asked, should one answer it? After all, the copyright librarian likely does not necessarily know, initially, whether or not the work the patron or coworker claims is original, so there is an argument for not answering until more information is available. On the other hand, said Crews, librarians are in the business of answering questions, so there is an equally compelling argument for giving the best answer you can with the information you have. If this were the case, Crews recommended the copyright librarian state plainly that they are not a lawyer, and are unqualified to give legal advice, but to then give the questioner some general advice or recommend a reference source for them to do further research.

Alternatively, Crews recommended giving advice in hypothetical terms, for instance, 'if this is an original work, then you get copyright protection automatically.' This approach was presented as a best-of-both-worlds compromise approach: avoid giving legal advice while still providing a sufficient answer. However, for many librarians, this type of hypothetical answer might seem hollow and unsatisfying. Crews addressed such concerns by positing another approach: answer to the very best of your abilities. The argument one can make for this approach provides adequate, and tempting, justification. One can get the same information with sufficient research on the Internet, after all.

There were, however, examples of instances in which a copyright librarian should exercise great caution when approaching a copyright question. These instances can go beyond the clear-cut case of a patron asking for legal advice. For example, Crews presented a scenario in which a 


\section{ACCEPTED MANUSCRIPT}

copyright patron approaches the copyright librarian and starts explaining their situation without discretion, giving the copyright librarian more information than they should or want to have. In this case, Crews invoked professional ethics, explaining that the copyright librarian should go to great lengths to explain that the conversation is not legally privileged, although they will do everything possible to protect their privacy in a non-legal sense. That way, Crews explained, the librarian will have done all they can or should ethically do when, as Crews stated, "the subpoena arrives."

Crews ended by asking the question are we looking at and dealing with copyright in the way that lawyers do? By this, Crews was not suggesting that librarians necessarily should. In fact, since it was obvious that the majority of librarians and interested parties present did not have a law degree, the question seemed more rhetorical than literal, proposed mainly to emphasize the differences in responsibilities between lawyers and copyright librarians.

Copyright law \& policy: Advocating for libraries

Carrie Russell (director for the Program on Public Access to Information at the American Library Association's Office for Information Technology Policy (OITP)) discussed the legislative progress of librarians who are advocating for libraries on Capitol Hill. Russell emphasized first that organizations such as the Association of Research Libraries (ARL), the Library Copyright Alliance (LCA), the Association of College \& Research Libraries (ACRL), and the American Library Association - Washington Office (ALA-WO), are the best way to have impact on legislative copyright decisions. 


\section{ACCEPTED MANUSCRIPT}

Russell's acknowledgement that copyright in Washington is highly political came as no surprise to the forum. The U.S. Copyright Office has an agenda, said Russell, which does not necessarily include putting libraries and library patrons first. The Office favors rights holders, according to Russell, largely because many U.S Copyright Office officials have previously worked for authors' associations. Moreover, Russell stated, the legislative players such as senators and Congress prefer to maintain the status quo and want Internet companies to police the web. Meanwhile, new companies and innovators demand flexibility in testing new business models.

This is the legislative environment, according to Russell, in which library advocates are operating in Washington. There is mistrust, it seems, between creator organizations such as the Author's Guild and library advocating bodies like ALA. This leads to confusion and alarm among legislators that librarians want to get rid of copyright. There is also a cognitive disconnect surrounding the idea that libraries lend out books for free. Russell said that another misconception leading to mistrust in Congress is the digitization movement in many libraries. Some nay-sayers believe that librarians truly desire what amounts to intellectual property piracy in putting content online, full-text and freely accessible, not understanding that for copyrighted materials libraries wish to provide an index to materials, facilitating discovery.

Russell explained several things that are currently being advocated for in Washington, beginning with the modernization of the copyright office. Specifically, she said, her program advocates for the United States (U.S.) Copyright Office to be independent from the Library of Congress. This change, said Russell, would allow the Copyright Office more independence, power, and autonomy. Additionally, according to Russell, the Copyright office would have the ability to spend its own funds and spend them on modernizing equipment and technology. 


\section{ACCEPTED MANUSCRIPT}

The next cause Russell advocated was the ratification of the World Intellectual Property Organization (WIPO) Marrakesh Treaty. The Treaty would require exceptions in copyright law worldwide in order to facilitate access for "blind, visually impaired, or reading disabled, or persons with a physical disability that prevents them from holding and manipulating a book" (World Intellectual Property Organization, 2013). This ratification, explained Russell, would help address the "book famine" in developing countries worldwide. In order to take effect, the Treaty has to be ratified by a minimum of twenty nations, as well as WIPO. Russell was optimistic about the ratification of this important treaty, and with good reason. As of this writing, the treaty has been ratified by the twentieth key nation, Canada, and was successfully brought into force as of June 30, 2016 (World Intellectual Property Organization 2016).

Above all, Russell stressed what she called the "cold hard truth" in library advocacy sometimes, it will not make any difference. Legislative changes come about slowly, if at all, and are typically out of date by the time they are signed into law. This is especially true when it comes to advocacy for technology in libraries, so library advocates must practice their advocacy on the frontlines. Ending on an inspirational note, Russell emphasized the obligation of librarians in fighting for the information rights of the public. Finally, she called for librarians to fearlessly embrace the grey area in copyright law when it comes to advocating on behalf of freedom of information.

References 


\section{ACCEPTED MANUSCRIPT}

World Intellectual Property Organization. (2013, June 27). Marrakesh Treaty to Facilitate Access to Published Works for Persons Who Are Blind, Visually Impaired or Otherwise Print Disabled. Retrieved from http://www.wipo.int/treaties/en/ip/marrakesh/

World Intellectual Property Organization. (2016, June 30). Canada's Accession to Marrakesh Treaty Brings Treaty into Force. Retrieved from

http://www.wipo.int/pressroom/en/articles/2016/article_0007.html

Tracie Seurer

E-Resources Access Manager, Auraria Library, University of Colorado Denver

Denver, CO, 80204, USA; email: tracie.seurer@ucdenver.edu

Managing an open access fund: Tips from the trenches (contributed paper)

Lilian Hoffecker (research librarian at University of Colorado Health Sciences Library (HSL)), and Heidi Zuniga (digital resources librarian and senior instructor at HSL), presented "Managing an open access fund: Tips from the trenches." Together they coordinate management of an author fund for open access journals at HSL.

Hoffecker discussed open access (OA) literature, defined by Peter Suber at the Harvard Library Office for Scholarly Communication (OSC), as literature which is digital, online, free of charge, and free of most copyright and licensing restrictions. Many of these OA journals follow the "author pays" model, where the author pays a fee in order to ensure free access to the reader. However, she added, in an OA fund, the institution provides financing for the article processing charge (APC), which could range from a few hundred to several thousands of dollars. Hoffecker 


\section{ACCEPTED MANUSCRIPT}

believes that one of the drivers of the OA movement is the transfer of copyright by authors to publishers at the time of publication.

In the interest of time, conference attendees were given a handout with three questions to ponder and discuss during lunch. They were as follows:

(1) Are libraries paying twice by having an OA fund, as a subscriber to a journal and sometimes funding the APC for the same journal?

(2) Should librarians encourage green OA instead of gold OA so that authors can retain copyright?

(3) Instead of paying the publishers, can libraries financially contribute in another way that prioritizes the author and the reader over the publishers?

The HSL open access fund started in 2013 as a result of growing familiarity with and interest in publishing in OA journals, combined with a lack of funding. The program runs twice a year and is funded through the library budget. To request funding, applicants must be an affiliate of the HSL campus and the corresponding or first author. The journal must be fully OA, articles must have been submitted or accepted with no other funding source, and the applicant must deposit their article in HSL's institutional repository. Priorities are given to students, residents, and other faculty. If an applicant qualifies, the full APC is funded.

Zuniga reported that $\$ 37,576$ of the allocated $\$ 50,000$ was expended during the last 3 years with 39 applications funded. Most of the funding was awarded to students, although faculty and residents also received a significant portion. She noted the top awardees by publisher, with PLOS leading this category. 


\section{ACCEPTED MANUSCRIPT}

[insert Figure 1 here]

Zuniga concluded the presentation with lessons learned from managing an open access fund. She recommended having an accounting staff member on the team to facilitate timely payments to the publishers, who will not publish the article until they receive payment. If there is a misunderstanding of the rules, Zuniga suggested creating a LibGuide in the event anybody challenges the fund. Here is a link to HSL's Open Access Fund LibGuide: http://hslibraryguides.ucdenver.edu/openaccess/fund.

\section{NASIG Annual Conference}

Maria Aghazarian

Serials and E-Resources Specialist, Swarthmore College, Swarthmore, PA 19081, USA; email: maghazal@swarthmore.edu

The North American Serials Interest Group (NASIG) 31st annual conference, "Embracing new horizons" was held in Albuquerque, New Mexico, June 9-12, 2016.

Providing and maintaining access to electronic serials: Consortium and member university library's perspectives

The session "Providing and maintaining access to electronic serials: Consortium and member university library's perspectives" featured three speakers: Wei Zhao (senior metadata librarian for Ontario Council of University Libraries (OCUL)), Shuzhen Zhao (bibliographic services librarian, University of Windsor), and Katie-Scarlett MacGillivray (coordinator of customer engagement, Brantford Public Library). Their presentation covered the various challenges that 


\section{ACCEPTED MANUSCRIPT}

arise when providing eresources within a consortium, and how it affects their workflows. They also discuss how this process changes through the migration of their integrated library system (ILS) to Alma.

Wei Zhao began by giving some context to the way that the OCUL functions and how they maintain their digital repository ScholarsPortal (SP). OCUL developed and maintains SP, which includes ebooks, ejournals, usage statistics, interlibrary loan functionality, and research data management. SP is the first certified trustworthy digital repository in Canada, with all of their ejournal content purchased, loaded, and housed within the SP platform. Holdings from SP are then exported to SFX, EBSCO, Keepers Registry, and 360 Link to populate the catalogs and link resolvers of the member libraries. Each member library of the consortium has its own SFX instance and is responsible for maintaining its own non-shared data within SFX. A central OCUL office manages the shared data using two physical servers: one to support local instances and the other to support the shared resources.

The SFX menu for each institution includes both local subscriptions from the member library as well as the shared data purchased by the consortium that is stored in the SP repository. The SP package of titles is treated in SFX as a target, and each school has a local version of this target so that it can be further customized for their institution. This customization allows librarians to adjust the holdings of SP journals to avoid overlap with their existing resources and subscriptions. However, there have been some problems in the way this practice is done through SFX. One problem is that when holdings data are exported from SP to be loaded into SFX, gaps in resources are not identified in these holdings. If a patron finds a citation for an article missing from the journal content in SP, the librarians configure the link resolver to link to the table of 


\section{ACCEPTED MANUSCRIPT}

contents for that journal issue in order to avoid linking errors. The librarians then need to request the missing content from the publisher.

Another problem is that some of the ejournals in the SP package duplicate international standard serial numbers (ISSNs) when loaded into SFX, because the object matching occurs based on the ISSN. Some of the journal records from the SP content only had a print ISSN or an eISSN, and SFX cannot recognize them as being the same object. Thus, the load created duplicate content, which meant that the ISSNs needed to be merged in each record. This is also problem with title changes for a journal because it creates two different holdings when the preference would be to display them as one for the clarity of the patron. For example, the SFX menu displayed the journal Biological Chemistry as if it was only available in SP for the year 2007, because that year falls under a different ISSN. Among the 19,000 journals, about 200 journals had this duplicate ISSN issue and required cleanup. A further problem is that this de-duplication needed to be done manually because SFX only allows holdings to be batch updated or batch revised, not ISSNs.

Shuzhen Zhao presented next with the perspective of consortium member Leddy Library at the University of Windsor. From 2000-2014, Leddy Library used SFX as their link resolver. In 2014, they decided to purchase Alma and Primo as early adopters. They lost SFX due to budget constraints, and they could not afford to maintain both Alma and SFX. This change of workflow created a labor-intensive process to edit records to be suitable for use by library patrons. Alma has three knowledgebase "zones" which are used in different ways. The Institution Zone serves as the member library's catalog. Each member library has a lot of flexibility in this zone and can do whatever they need to do here, including managing bibliographic records, uploading and downloading content, and maintaining licensing agreements. The Community Zone serves a 


\section{ACCEPTED MANUSCRIPT}

similar function to SFX, but not completely the same. The member libraries cannot update the records but only make local notes. This zone is managed by Ex Libris and relies on voting from different customer libraries in order to make significant changes. For example, a request for a new target needs to be sent to Ex Libris to be made available for voting. At 10 points per institution, cases open for voting need to hit 400 points in order to be considered. However, OCUL cannot often afford to wait for this process to occur; they need immediate access once they have purchased a package. The last of the three zones is the Network Zone, which is still in progress. This zone will act as a shared catalog among all customer university libraries, and will include the ability to download records. As such, this zone could be used as an important alternative to OCLC; OCLC membership fees for Zhao's library have risen by $800 \%$, and they are considering cancelling. Within Alma, SP functions as a local package in the Institution Zone. Zhao also presented the purchasing and invoicing workflow for a member library to pay for content provided by OCUL.

Katie-Scarlett MacGillivray presented next on four challenges for member libraries that arose after the migration to Alma. The first challenge was a discrepancy in the number of journal titles represented for SP. SP has 13,940 titles, but when it was loaded into the Institutional Zone for Leddy Library, it resulted in only 13,698 titles. These journals must be compared on the titlelevel in order to close the gap of 251 titles. The second challenge is the necessity of maintaining holdings on a local level. This is a particular problem with titles that have moving walls. Librarians at the university receive regular error emails about access issues for current issues; these holdings must be fixed individually. The third challenge is the difficulty in balancing agreements with vendors between what is purchased as an individual library and what OCUL 


\section{ACCEPTED MANUSCRIPT}

purchases for all member libraries. If a member library subscribes to a package that OCUL later negotiates for SP, then the member library is invoiced as if they are paying for the same content twice in one year. Librarians then need to negotiate credit with the vendors, which is essential for tight budgets. The last challenge MacGillivray discussed was the general administrative challenges in working with such a widely geographically distributed consortium. This physical distance creates its own set of challenges in communication among member libraries and between member libraries and the OCUL office.

The presenters reassured attendees that there are still many advantages to consortial purchases such as saving money, sharing records, collaboration, and creativity. In the questions portion of the presentation, Zhao clarified the process and challenge of correcting the duplicate ISSNs in Alma. From Alma's perspective, SP is treated as an access publisher. When updating the title list for SP, sometimes a journal will only be associated with a print ISSN or an eISSN, even though the same journal is already represented in Alma with slightly different information. Journal subtitles cause similar problems. Even though the member libraries pay for this content from OCUL, the titles must be individually activated in Alma after purchasing. Another question arose regarding the length of OCUL negotiations and whether it has ever impeded a member library's plans for renewals. Zhao explained that all member libraries vote for the licenses they want. Her library decided to purchase content from Alexander Street Press outside of the consortium. However, this means that her library had to locally load bib records and holdings into Alma since they could not rely on the Community Zone for those records. Another audience member asked about gathering usage statistics for both SP and other licensed content. Alma provides statistics on full-text downloads for SP and similar reports from the publishers. Since SP is its own 


\section{ACCEPTED MANUSCRIPT}

platform with locally loaded and purchased content, librarians at member libraries try to prioritize SP and increase usage by making sure it lists at the top of their link resolver menu. They are currently conducting a survey with students and faculty addressing link order preference in this menu.

Embracing the zines: Zine acquisitions and cataloging at the Vassar College Library Heidy Berthoud (head of technical services, Vassar College) presented "Embracing the zines: Zine acquisitions and cataloging at the Vassar College Library." She began by providing some context of the student culture and campus environment at Vassar. With a very socially active campus, it made sense that Vassar students would be interested in zines, which are self-published materials that may address a range of personal themes such as gender and ethnic identities. Vassar's zine collection contains 182 cataloged zines, but there are nearly as many in Berthoud's office waiting to be cataloged. It is a relatively new collection and has been public since August 2015. Berthoud is responsible for selecting, acquiring, and cataloging the zines. Her presentation covered the basics of these responsibilities, as well as some of the challenges that arise in handling zines compared to handling more traditional library acquisitions.

Zine acquisitions follow a different business model than traditional publishing in that zinesters (zine creators) do not make zines for profit. As such, marketing for zines is not designed to attract sales. None of the traditional collection development resources exist for zines--there are no catalogs or email lists to market them or keep up with new publications. Berthoud presented a few different options for zine acquisitions, prioritized to be respectful to the zine creators. The preferred mode of acquisition is to purchase directly from the creator. When this is not possible, one may look for a zine distributor, or distro, in order to purchase zines. Standing orders or 


\section{ACCEPTED MANUSCRIPT}

subscriptions are not offered in the zine world, so keeping up with serial-like publications is the responsibility of the purchaser.

An important aspect of zine acquisition is to give the creator the right of refusal. Zines may cover very personal topics, and not everyone will want their work to be publicly available, so the creator needs to know that the zine being purchased is for a library. In Berthoud's experience, no zinester has yet objected; in fact, some zinesters have been very excited about the prospect and have added in extra goodies with the zines. Berthoud has at times received free zines, thank you notes, stickers, buttons, and even a t-shirt. This may be an unexpected surprise for many librarians, and Berthoud noted that there should be a designated place in the library to collect this ephemera. Since the preferred route of acquisition is directly through the zinester, Berthoud recommended Twitter, Etsy, and tumblr as tools for searching for creators. Some organizations exist to boost the work of creators despite not being a distro; POCZineProject is an example of this, and they are on tumblr, Twitter, and Facebook.

Cataloging zines is a practice in concession: “catalogers' purgatory" may exist, but "we're all going there." Rather than worry if the cataloging is perfect according to cataloging rules, worry about whether or not the record is perfect for the zine itself. Berthoud again emphasizes to "just embrace catalogers' purgatory." In authority records that currently exist for zinesters, some of the records use subfield c (\$c) for "(zine author)." However, this practice lacks consistency, and it is unclear if it will remain in the records or persist as a practice. Vassar is not a Name Authority Cooperative Program (NACO) for the Program for Cooperative Cataloging (PCC) contributor, so Berthoud keeps track of authors through a local authority file in Excel. In this spreadsheet, the author's pronouns are also noted if they are known at the time. 


\section{ACCEPTED MANUSCRIPT}

In regards to cataloging the objects, xZINECOREx is a metadata standard developed at a zine librarian unconference in order to address zine metadata in a schema based loosely on Dublin Core. Through discussion at the unconference, Berthoud explains that the ideal way to tackle zine cataloging seems to be forming a union catalog outside of OCLC. When cataloging, note freedoms and restrictions: is copying or reproducing allowed? While this is important for preservation, some zines are created with the explicit purpose of being widely copied and redistributed. Trigger warnings are recorded in the bib record, but only if they are printed on the zine itself; they are not applied by the cataloger. When assigning subject headings for zines, librarians should approach this as an opportunity to fight systematic and personal biases. This is a nuanced, complicated process, and while difficult and time-consuming, it is definitely worthwhile.

As mentioned before, social justice is a high priority for Vassar students, so it makes sense for Berthoud to collect zines in these areas. Because the collection focuses on diverse publications, the cataloging should reflect these values. In contrast, Library of Congress Subject Headings (LCSH) lack subtlety and clarity. In trying to assign subject headings to publications, Berthoud has found that the structure of LCSH implies that certain identities cannot coexist, citing the scope note for "indigenous women." The way that LC describes and separates [ethnic] identities rarely lines up with the way a zinester recognizes and describes their own identities. LCSH is not very nimble in this way, especially when describing a diversity of genders. However, rather than disregarding LCSH altogether, catalogers should carefully scrutinize these headings and the process of assigning them. Berthoud gives the following example for a gendered subject heading: "transsexual" is a LCSH, but it should not be used for a zine unless a zinester explicitly identifies 


\section{ACCEPTED MANUSCRIPT}

this way. This is where local headings have great importance. Some common ones Berthoud uses include "white privilege" and different headings around gender non-binary identities. She emphasizes: "I would much rather be true to the resource than true to the cataloging rules."

Because cataloging is such a nuanced process, summaries and keywords are very important for discoverability and tackling some of these issues of classification. Use of genre headings is especially important; some common genres of zines are personal zines, political zines, compilation zines, do-it-yourself (DIY) zines, and fanzines. A lot of this cataloging work is done by student interns, also known as zinterns. One of the zinterns even wrote his thesis on archived identities and zines.

Berthoud concluded by passing out an activity with several examples of different zines. One of the examples was a serial-like zine that went through a title change, and Berthoud was interested in how others would catalog this.

[insert Figure 2: First page of the zine Observation, previously titled Observations.]

In the questions section of the presentation, Berthoud addressed the scholarly application of collecting zines. She has been invited to present on the library's zines for several courses, including women's studies courses. One course even changed their final project from a poster to creating a zine as a result of the presence of the zine library on campus. Berthoud says that when the library collects zines, it sends a message to students that "your stories matter, too," and that the library is interested in curating and archiving these stories.

Rachel Becker

Electronic/Continuing Resources Librarian, University of Wisconsin - Parkside, Kenosha, Wisconsin, 53140,USA, email: beckerr@uwp.edu 


\section{ACCEPTED MANUSCRIPT}

The NASIG conference's vision sessions focused on emerging issues in electronic and serials resources. These issues included the impact of open access in institutional repositories, the benefit of open access publishing in advancing health research, and improving collaborative interlibrary loan borrowing.

The power of open

Heather Joseph (executive director of the Scholarly Publishing and Academic Resources Coalition (SPARC)) presented, "The power of open," SPARC's motto is "set the default to open" meaning they would like to see all scholarly articles published openly automatically unless a good reason exists to keep them behind a paywall. Previous to SPARC, Joseph worked in journal publishing for 15 years, including as the publishing director at the American Society for Cell Biology. In addition, she serves on many boards to promote open access publishing in all academic fields and especially in the sciences. Through her efforts more science journals are moving forward with open access and leading to faster innovation in the medical field. Joseph discussed the importance of keeping research and scholarly materials away from restrictive paywalls. She cited the Budapest Open Access Initiative (BOAI) and its goal of advancing scholarship for the purpose of providing a public good rather than producing a commodity. Joseph highlighted the importance of the BOAI as setting a framework for OA for the future. This meant immediate open access to the relevant information on the internet that scholars and researchers needed to "solve problems." The problems are different depending on what field researchers are working. Joseph cited the example of rising journal prices for librarians. This is particularly the case in the sciences as these fields change rapidly and produce a larger volume of literature than other fields. Institutions such as Harvard University have built 


\section{ACCEPTED MANUSCRIPT}

OA into their mission and use it to drive research. Other organizations use OA to promote research into public health and see it as a public good.

One of the problems with the OA movement that Joseph sees is the fragmented approach between open access research, open access textbooks, and open access journals. Although all of these are legitimate approaches she views this as one of the main hurdles of the current OA movement. She identified four strategies for SPARC to focus on regarding OA: 1) look at the whole board, 2) clearly define our end goal, 3) explain why "open" is vital, and 4) reward "open" in meaningful ways. The SPARC website (http://sparcopen.org/) focuses on these four strategies to meet their goals. Finally, Joseph discussed Vice President Joe Biden's Moonshot Initiative, which he started after he lost his son to cancer. This initiative aims to remove barriers toward cancer research and achieve the same advancement toward finding a cure in five years that would normally take ten. SPARC reached out to the Moonshot Initiative and put forward a recommendation to make some cancer research open access. Currently, the Vice President is promoting these recommendations and promoting these policies. Joseph is hopeful that this will be a major advancement for OA.

Gordon Coleman

Head, Acquisitions \& Serials, Simon Fraser University Library, Burnaby, BC, V5A 1S6; email gcoleman@sfu.ca

Embracing changing technology and new technical services workflows in migrating to a nextgeneration library management system

Jessica Ireland and Kay Johnson from Radford University's McConnell Library presented on their experiences in migrating to OCLC's WorldShare Management Services (WMS) in 2015. 


\section{ACCEPTED MANUSCRIPT}

The migration involved merging several separate systems such as the knowledgebase (KB) into a single system. Radford University has approximately 10,000 students. The library has 35 faculty and staff positions including ten in the collections and technical services department. Johnson is the head of Collections and Technical Services and Ireland is the serials and electronic resources librarian.

The migration took place over a ten-month period from the announcement in February to go live the following December. The first discovery was which record types would migrate (bibs, items, holdings, patron data, and circulation data) and which would not (acquisitions data, the knowledgebase, eresource management system (ERMS) data, check-in records). These limitations dictated some steps in the migration process. For example, it was necessary to barcode and create item records for all bound journal volumes, and a temporary assistant had to be hired for this work. Various local notes in check-in records needed to migrate as well. The pre-migration serials project did allow for some weeding, especially of journals available online in JSTOR.

Regarding the knowledgebase migration, a decision was made to cancel the contract with the previous supplier. This meant a very short timeline to grab data from the KB and then manually reactivate the same resources in OCLC's Collection Manager tool. An automated importing process was not possible because this would have created custom local collections that would not be maintained by OCLC. Collection Manager has a number of advantages including one-click activation and tight integration between orders and KB data. However, there are data quality problems in some of the collections, delays in updating, and poor search features. 


\section{ACCEPTED MANUSCRIPT}

Training began in September. There are many excellent training videos on the WMS site, and the speakers complimented OCLC on their great customer support. Radford migrated in a cohort with several other libraries. They received many useful tips from the libraries in the cohort. WMS facilitates this type of community-based approach. OCLC also sent consultants who carried out a two-day analysis to understand the library's workflows and then align those with the capabilities of the system. This occasioned "paradigm shifts" which were sometimes uncomfortable. For example, Radford had always separated the receiving and cataloging functions, but WMS combines these.

The second half of the presentation focused on the aftermath of the migration and the lessons learned. The presenters amusingly illustrated this with a photograph of a tornado. For example, there was a major clean-up task with serials records. For unclear reasons many local holdings records had been created. Serials work also involved adapting to some of the quirks in the new system, such as being unable to delete a received journal issue if another library has erroneously reported it was received. OCLC releases bug fixes regularly and it is hoped this one will be solved. Re-creating order records for subscriptions and standing orders was another major task. Five years of historical data was saved in spreadsheets for consultation if necessary. WMS has a very different approach to order records, with a single purchase order housing many payments related to the same vendor. This is conceptually very different than the library's previous structure (order records attached to bibs).

Overall the migration was successful. Almost all bibs matched successfully against OCLC, and they even launched two days early. Much time is being saved with authority work and eresource management. The experience brought staff together, strengthened relationships, and allowed for 


\section{ACCEPTED MANUSCRIPT}

re-evaluation of workflows. The new system also runs well across all browsers and devices. The fact that the system is continually evolving and acquiring new features is both a plus (continuous improvement) and a challenge. There is still a lot to learn. As one presenter commented, "We're doing fiscal close in July. I hope it works."

Ireland and Johnson ended the presentation with a slide of lessons learned. They suggested starting the migration early, cleaning up legacy data such as location codes, finding a way to extract critical data that may not migrate, meeting often, learning from everyone, and being tolerant of mistakes. They have plans for several follow-up steps as they transition from postmigration firefighting to a sense of stable new workflows.

\section{Leigh Ann DePope}

Electronic Resources Librarian, University of Maryland College Park, College Park, MD 20742, USA; email:ldepope@umd.edu

Master of "complex and ambiguous phenomena": The ERL's role in library service platform migrations

Kirsten Ostergaard (electronic resources and discovery services librarian at Montana State University), and Conor Cote (electronic resources librarian (ERL)) at Montana Tech of the University of Montana), presented on a consortium-wide library service platform migration and how the NASIG core competencies for electronic resources librarians help develop their role in the migration. Ostergaard and Cote started off by defining two terms: library services platform and librarians. Library services platform is a term coined by Marshall Breeding to describe the new suite of next-generation library products. For the scope of Ostergaard and Cote's 


\section{ACCEPTED MANUSCRIPT}

presentation, the term "librarians" encompasses all library professionals and staff involved in library operations. They also conducted a brief poll of the audience to see who was currently participating in a migration process, if the migration was with a consortium, and to what platform they were migrating.

Ostergaard and Cote next provided some background on their universities and on their migration project. Montana State University has approximately 15,000 full-time equivalent (FTE) students. Their integrated library system is Ex Libris's Primo. Montana Tech, with approximately 2500 full-time equivalent students, is using Ex Libris's Voyager integrated library system and Primo discovery system. Both schools are members of the new Treasure State Academic Information and Library Services (TRAILS) system. TRAILS is a seventeen-member consortium comprised of academic libraries, private college libraries, community college libraries, and several other academic-related institutions across the state of Montana. The consortium began the migration project in 2015 by issuing a request for proposals (RFP) which were reviewed during the fall with the selection of Ex Libris's Alma library services platform being made in December. During the spring of 2016, planning began for the migration, which kicked off on the first of May. The migration team has a firm deadline to complete the migration by December 2016 due to the expiration of contracts for several existing legacy systems.

Ostergaard and Cote briefly discussed a literature review they conducted for both the migration project and this presentation. The first article explored the follow up work that needed to be done after a migration was complete, which showed that $25 \%$ of the remaining issues involved eresources. Electronic resources issues were also the largest type of any issue reported. For the presenters, this indicated that ERLs have to put in the most time and will play a central role 


\section{ACCEPTED MANUSCRIPT}

during a migration project. The next article focused on communication in library consortia. The takeaways from this article were that consortia have a need to communicate a wide variety of messages to a large number of library staff at all levels in each member library; therefore, strong communication is needed among all stakeholders. The final article discussed a shared integrated library system migration process. For Ostergaard and Cote, the relevant points from this article centered on how to effectively manage people for a successful migration process.

The majority of Ostergaard and Cote's presentation concentrated on how each of the seven NASIG core competencies for electronic resources librarians applied to a library services platform migration. They reviewed each competency and pulled out only those characteristics that seemed related to or significant for a migration project. The first core competency addresses the lifecycle of eresources. The overall characteristic from this competency that applied to their project was that eresources librarians act as a bridge across departments. The new platform can be very different from the old one, which creates a high learning curve. They relied on their colleagues for support in adjusting to the new system, as well as the support offered through their vendor's services. The feedback they received from each other helped to inform the testing of the new system and the implementation of customized features.

The second core competency focuses on technology and enhances how electronic resources librarians require "theoretical and practical knowledge of the structures, hardware, and software" that allow for access to resources. Migrations are naturally disruptive to established workflows, and they cause a significant impact on staff morale. The technology skills ERLs possess equip them with the ability to learn a new system, train others on the system, and respond to questions about the functionality of the system. 


\section{ACCEPTED MANUSCRIPT}

The third core competency covers communication. Ostergaard and Cote found this to be the most relevant competency for the migration project. The key phrases they took from the characteristics of this competency were "communicate effectively, promptly, and consistently" with both internal and external audiences, "synthesize easy to understand summaries of complex and ambiguous phenomena," and "ability to work collaboratively with other units." The communication structure for their migration project started with a core team and their vendor, Ex Libris. The core team communicated with two groups: the functional teams and the library contacts. Both of those teams facilitated the internal communication of each consortium library. Cote discussed the components of the functional teams and the teams' roles. The library contacts served the pathway for each library to receive both key and general updates on the project. Functional team communication was conducted through BaseCamp, a project management software system, which only team members could access. Through BaseCamp, they communicated key information about the status of the migration, functional aspects of the system, task deadlines, and project calendars. Some information was also sent via email. For Cote, internal communication with his staff was trickier. He talked to his staff, offered them communication options, and requested their feedback. His staff indicated that they did not want to learn yet another new system. They wanted something familiar. Ultimately, they used Microsoft OneDrive for Business and OneNote specifically. OneNote acts as a central location for all information and promotes transparency while reducing the amount of emails staff received.

The fourth core competency discusses research and assessment characteristics. The characteristics that the presenters felt were most relevant to their project included problem 


\section{ACCEPTED MANUSCRIPT}

solving, analytical skills, and aptitude for detail-oriented work. Electronic resources librarians do a great deal of troubleshooting and communicating with vendors about problems with eresources. To facilitate the communication of migration or system functional problems amongst the consortium libraries and the migration project team, a set of internal tools were developed. A unique aspect of their migration was that the vendor requested only one person be identified per library to submit support tickets. This put extra pressure on the support person to communicate with and develop an understanding of other areas of the library outside of their personal expertise.

The fifth core competency focuses on supervising and management. According to Ostergaard and Cote, the characteristics of this competency that the ERL demonstrates are the ability to train, supervise, and motivate staff, "skillful project management," and the ability to evaluate existing processes and workflows. Ostergaard indicated that employing time management skills was the most important management aspect relevant to their project. Team leaders needed to set deadlines, assign tasks, and ensure that tasks could be completed and the deadlines met. This aspect also included managing people from other departments or libraries that team leaders were not accustomed to managing.

The sixth core competency covers trends and professional development and the ERL's "commitment to ongoing professional development" due to the constant changing nature of eresources. Ostergaard noted that this characteristic is underrated, which was apparent in their project. The Alma system has been evolving as the migration has progressed. As staff members were learning the functionality of the system, the system itself was changing. The team leaders 


\section{ACCEPTED MANUSCRIPT}

had to keep up with the release notes from the vendor and provide training as new content developed.

The seventh and final core competency discusses the personal qualities an ERL exhibits. The central characteristics Ostergaard noted were "flexibility and open-mindedness," "ability to function in a dynamic, rapidly changing environment," and having a "high tolerance for complexity and ambiguity." These qualities make the eresources librarian perfectly positioned to offer a high level of customer service to both colleagues and patrons. To demonstrate this, Ostergaard referred to a presentation at the 2016 Electronic Resources and Libraries conference by Gallagher and Hosburgh on the concept of emotional hijacking. During a migration project, staff can be overwhelmed by fear of the unknown and fear of being replaced by the technology. Eresources librarians have the ability to lead with respect and exercise empathy while guiding people through the migration process.

For Ostergaard and Cote, the key takeaways from this examination that can be best used in a migration project are to lead with respect, keep the end goal of the project in mind, advocate for transparency, tailor communications to the audience, tailor what staff members need to know based on their individual perspectives, ask for feedback, and be open to criticism. Ostergaard and Cote set out to see how the NASIG core competencies would relate to a migration project. They feel that the competencies serve as a good framework to prepare the ERL for their role in a new library services platform and lay the groundwork for approaching a migration project.

Adventures in licensing! How librarians are embracing and affecting change in electronic resource licensing 


\section{ACCEPTED MANUSCRIPT}

Lori Duggan (head of electronic resources at Indiana University), Christina Geuther (electronic resources librarian at Kansas State University), and Corey Halaychik (electronic resources and serials librarian at University of Tennessee Knoxville), gave a presentation on various areas of electronic resources licensing. Duggan's segment focused on licensing issues with international publishers. Next, Geuther discussed licensing workflow changes stemming from a library resources management system migration, and Halaychik explored developing master license agreements.

Duggan began the presentation by explaining how Indiana University handles licensing. Indiana University has autonomy over the licensing process. They negotiate licenses for electronic resources, have signatory authority to sign the licenses, and can process the invoices for those resources. Routine meetings are held between the acquisitions department, the university purchasing department, and university legal counsel to discuss licensing related issues and procedures. After a meeting between these groups, Duggan worked with a university attorney who specialized in international business contracts to become more familiar with areas of concern particular to international business transactions.

Duggan identified three top areas of concern to consider when working with international vendors. They are transactions that require consultation with legal counsel before licensing a resource, new terms or language that are unique to international purchases, and different ways certain terms, such as jurisdiction or governing law, are applied. Before Duggan continued, she reminded the audience that her talk covered local practices and all librarians should discuss these issues with their own university's legal counsel. 


\section{ACCEPTED MANUSCRIPT}

One of the most serious issues that requires consultation occurs when purchasing a resource from a country on which the United States has imposed sanctions. Duggan discussed two types of sanctions: selective sanctions and comprehensive sanctions. Comprehensive sanctions are the most restrictive and block all trade with those countries. Selective sanctions are less restrictive and allow for some trade. In these situations, Duggan consults her legal counsel before considering a purchase. Another situation that requires consultation involves the United States Foreign Corrupt Practices Act. This act serves to protect the ethical nature of a transaction. A vendor could be a foreign official, and purchasing something from them could be considered bribery--that is to say, giving a foreign official something of value. In most cases, library materials would not necessarily be considered something of value, and the likelihood of this situation occurring is low. Duggan would again consult with her legal counsel before continuing with a purchase.

Duggan concluded her segment by discussing the language issues that raise concerns. The first language pertains to the United States anti-boycott law. This law prohibits the licensee from doing business with certain countries or entities that either refuse to do business with certain groups (based on race, religion, or other factors), or restrict the licensee from doing business with those groups. Agreeing to this language in a license would violate United States law. Other concerns center on the language for jurisdiction and arbitration. Indiana University prefers to list the state of Indiana for jurisdiction or to remain silent; for arbitration, they also prefer to remain silent. These preferences change slightly for international licenses. Jurisdiction language referring to the state of Indiana is still the first preferred choice, but for international licenses, 


\section{ACCEPTED MANUSCRIPT}

arbitration is the second preferred choice. Anything other than those two options is referred to legal counsel.

Duggan noted that she has been using these practices for the last year and no licensing negotiations have failed nor have any major problems arisen. However, she did explain that these practices can protract the licensing and acquisitions processes.

Geuther spoke next on the adaption of licensing workflows stemming from a library services resource management system migration. Kansas State University library migrated from Ex Libris's Verde electronic resource management system to Alma, Ex Libris's next-generation library resource management system. Geuther, as the eresources librarian, performs the entire licensing process with some consultation with legal counsel. The normal workflow process includes modifying terms as needed when negotiating licenses, incorporating license details into the electronic resources management system (ERM), storing static license agreements and correspondence about licenses, and revisiting documentation as needed when renewing resources.

In the clean-up work that followed the system migration, Geuther developed a procedure for handling workflows that fall outside of the normal path, and she developed best practices for all license workflows. The four key elements of the alternative workflow include continuing to follow established best practices as closely as possible, creating a standard process of the type of situation at hand, developing documentation on the workflow, and building consistency for the workflow. For the best practices, she and her colleagues are establishing and following a 


\section{ACCEPTED MANUSCRIPT}

collection development policy for licensing, using a checklist to look for required or problematic language, and maintaining documentation on licensing activity.

Geuther then discussed three specific situations that require an alternative workflow. The first of these situations is a clickwrap license. A clickwrap or click-through license is commonly used with software in which a user agrees to the terms by clicking an "I Accept" button. In order to document the terms, Geuther captures an image of the license from the screen, notes the date, and attaches the image file to the record in the ERM. The next situation involves terms of use that appear on dynamic websites. This situation occurs when a publisher does not agree to negotiate a license nor participates in Shared E-Resource Understanding (SERU). Geuther can only work with this type of situation when no terms are present that violate state law or university policy. She follows the same procedure as with clickwrap licenses to document the terms to include in the ERM. The final situation happens with SERU. SERU is a standard to which both the publisher and library agree to adhere. When SERU is an available option, Geuther is able to readily agree to SERU language. The use of SERU is confirmed with the publisher through a signed invoice and/or through email with the vendor. Geuther also verifies that the publisher is in the SERU registry.

Geuther concluded with the following tips: use templates in the ERM to create uniform language, label SERU and other non-standard licenses in an obvious way, verify the license information in the ERM regularly as renewal periods occur, and review updates to the functionality of the ERM to see how the updates will affect the workflow. Following standard workflows resulted in increased documentation, made task management more effective, created 


\section{ACCEPTED MANUSCRIPT}

more transparency, and made more effective use of all modules in the electronic resource management system.

Halaychik concluded the session by discussing the development of institutional master license agreements to streamline the electronic resource acquisitions process. The University of Tennessee made the shift to streamline the workload created by university policy. Personnel in the library do not have the authority to sign license agreements. Anytime a new license was needed or a resource was renewed, the license agreement and all addendums had to be reviewed by several people in several university departments. University fiscal policies were restrictive, confusing, and ineffective. The review process was lengthy and perplexing. This process limited the library's ability to respond quickly to short-time offers from vendors, caused frustration for those managing the process, and ultimately damaged relationships both internally and externally. In partnership with the university contracts office, the library developed institutional master agreements to address all of those issues.

The institutional master agreements standardized the language and streamlined licensing workflow. The master agreement is a boiler plate template that addresses those provisions in a license to which a university cannot usually agree, such as indemnity and jurisdiction. The vendor terms are then attached to this template. This template is used across the University of Tennessee system. The use of this template reduces the number of times a license has to be reviewed down to one. It also streamlines the ordering process by allowing the library to work directly with the purchasing office. Finally, this template helped standardize the review process where the library now looks only at those terms related to library needs, and the contracts office looks at the terms relevant to the procurement process. 


\section{ACCEPTED MANUSCRIPT}

Halaychik concluded his talk by discussing the results for this new process. The process has been in place for three years. Over 150 agreements have been signed under this new process, including agreements with all major vendors. Agreements under the template cover all types of materials available. Using the template has reduced the volume of their licensing work by $55 \%$ and has saved around $\$ 63,000$ per year of staff time. The lessons learned from this process are be flexible, plan your timing to take advantage of offers, be persistent, and stay focused.

\section{Dianne Ford}

Coordinator of Library Electronic Resources, Elon University, Elon, NC, 27244, USA; email: dford@elon.edu

A dialectic on the aims of institutional repositories

T. Scott Plutchak (director, Lister Hill Library of the Health Sciences, University of Alabama, Birmingham) expressed the opinion that institutional repositories (IRs) have not been ideal depositories for faculty publications. Multiple versions of journal articles have created confusion about the version of record and which is best for the reader's use. Plutchak believes IRs should focus on materials outside the publishing stream, rather than duplicating OA material readily available from other sources. IRs are performing well in archiving work unique to our campuses and not published elsewhere, such as dissertations and theses, posters, and undergraduate research. He acknowledges, however, that long-term preservation has not been properly addressed for most IRs. There should also be a focus on building a network of open repositories; ResearchGate and Mendeley, for example, are more viable platforms than IRs for faculty research management. 


\section{ACCEPTED MANUSCRIPT}

Show me the value: Constructing an analytical tool for assessing a consortial serials package

Matthew Harrington (North Carolina State University) has done in-depth work constructing a return-on-investment (ROI) database for the NC Triangle Research Libraries Network (TRLN). He used Microsoft Access because of its good graphing potential to demonstrate the value of Springer and Wiley-Blackwell journal packages for the TRLN schools. Primary data sources were cost/use/institution, publisher list prices, and coverage dates. Data can be viewed by institution, illustrating low usage titles and average cost per use.

E-books for the classroom and open access textbooks: Two ways to help students save money on textbooks

Jason Boczar and Laura Pascual (University of South Florida) presented on how to help students withstand the rising cost of textbooks and support student success. The University of South Florida has implemented two eresource-based initiatives as part of the campus Textbook Affordability Project (http://tap.usf.edu/). Through the E-books for the Classroom program, the library purchases electronic versions of texts required for coursework, providing access to needed materials at no cost to the students. For the past five years, this program has evolved into a highly successful textbook affordability measure, acquiring hundreds of ebooks and serving thousands of students, as well as becoming an integral part of the ebook acquisition process. The library has had some success in publishers donating copies of textbooks for reserve. They are also funding the development of a new open access textbook by a faculty member, to be distributed via the library's institutional repository.

Embracing undergraduate research: Creating the arsenal 


\section{ACCEPTED MANUSCRIPT}

Melissa Johnson and Kim Mears (Augusta University, GA) explained how their library, in collaboration with the Center for Undergraduate Research and an interested student group, developed and hosted a new open access (OA) undergraduate research (UR) journal called Arsenal in the university institutional repository (IR). The library received an Institute of Museum and Library Services (IMLS) grant to build their IR, called Scholarly Commons. They looked at other models for UR journals, considering student-run, faculty-run, and hybrid models. A clear step-by-step process for developing a new journal was presented, including a creative commons license, faculty mentor consent form, and blind peer review. The new journal accepted submissions in January 2016; they are in the copyediting phase and hope to release their first issue by the end of summer 2016. Future directions include adding the journal to Directory of Open Access Journals (DOAJ), more marketing to create faculty buy-in, and implementing antiplagiarism software.

John Kimbrough

Electronic Resources Librarian, Georgetown University, Washington, DC; email: jwk77@georgetown.edu

The knowledgebase at the center of the universe

What is the center of the universe? For over one thousand years Earth was the fixed point around which everything in the heavens revolved. But in the 16 th and 17 th centuries, this view was challenged by increasingly accurate astronomical observations, leading to the rise of a new model of the solar system with the sun at the center. 


\section{ACCEPTED MANUSCRIPT}

Today a similar shift is occurring in the library universe, noted Kristen Wilson (associate head of Acquisitions and Discovery, North Carolina State University). For many years our "center" has been the bibliographic record, but this model is progressively unable to cope with journal titles that may have several access points with different coverage dates. Instead, the center of information is increasingly occupied by knowledgebases (KBs). A library's knowledgebase usually feeds other services, such as a link resolver or discovery layer - but libraries are also starting to use $\mathrm{KB}$ information in many other areas, including acquisitions, identity management, and usage statistics.

Ideally, metadata smoothly flows from content providers through KB vendors and ultimately to library subscribers. Actual reality is chaotic, as Wilson observed, with vendors facing an "uphill battle" to provide perfect accuracy in the thousands of packages and millions of records represented in their KBs. Knowledge Bases and Related Tools (KBART), a National Information Standards Organization (NISO) best practice for KB metadata, is helping to reduce errors by providing a standard format for publishers to provide metadata to knowledgebase vendors.

Many commercial KB vendors are positioning their knowledgebase within a constellation of related products. Wilson examined the offerings of two vendors (EBSCO and OCLC) and how each vendor links their knowledgebase to their other services. EBSCO uses its KB to combine data between its subscription agent service (EBSCONET) and usage reporting tool (EBSCO Usage Consolidation). Libraries subscribing to all three services can obtain rich analytical data, such as cost per use, and streamline processing workflows. OCLC's links between WorldCat, WorldShare Management Services, and its licensing manager allow licensing information to 


\section{ACCEPTED MANUSCRIPT}

inform interlibrarary loan (ILL) lending by using the knowledgebase to link these two products together.

What's new in knowledgebase development? Wilson focused on three interesting trends: data enhancement, application program interfaces (APIs), and collaboration. Data enhancement includes incorporating new types of information into KBs: new content types (e.g. audio), linked data relationships, including machine-readable cataloging (MARC) data in the knowledgebase record, and history/revision tracking.

APIs provide a programmatic/system interface into knowledgebase data. Libraries making use of API gateways into KBs include the University of New Brunswick, which built a custom discovery layer atop the WorldCat knowledgebase, and Wheaton College, which used their SFX knowledgebase to populate journal holdings in Browzine. Some vendors, such as Elsevier, are also using APIs to offer automatic populating of library-specific holdings.

Collaboration is a third trend in knowledgebase development, with libraries directly editing and maintaining a shared knowledgebase. Knowledge Base+ in the United Kingdom (UK), BACON (BAse de COnnaissance Nationale) in France, and ERDB-JP (Electronic Resources DatabaseJAPAN) in Japan, are all attempting to produce highly curated lists of regionally or nationally available journals. GoKB (The Global Open Knowledgebase), which Wilson previously directed, is a freely available knowledgebase tool that is community managed.

Librarians of tomorrow may use a single global knowledgebase, underlying local tools and resources. Although this may be a remote possibility, Wilson's presentation urges us to 


\section{ACCEPTED MANUSCRIPT}

reconsider the role of knowledgebases: not just as adjuncts to the catalog, but as the center of our bibliographic universe.

Text mining 101: What you should know

"I'd like to download as much as we can get of the Oxford Dictionary of National Biography," said a faculty member to Ethan Pullman (humanities liaison at Carnegie Mellon University (CMU) Libraries). Text mining — automated processing of structured digital texts—is a rapidly growing area of scholarship, requiring large datasets and specialized processing tools, and presenting challenging questions for both librarians and resource providers. The speakers (two librarians and two vendor representatives) provided a variety of perspectives on text mining. As a departmental liaison, Pullman often receives inquiries from faculty (and students as well) about text mining. The faculty request to mine the Oxford Dictionary of National Biography (ODNB) led to Six Degrees of Francis Bacon: an online interactive tool allowing researchers to explore the social network of early modern Britain. A second example is a recent class project that mined briefs and other legal documents in Authors' Guild v. Google, looking for rhetorical patterns. Although liaisons and public services librarians may not directly engage in text mining, it is an ongoing task to keep abreast of how texts are used, what tools are available, and issues impacting access to texts. Pullman stays informed by attending departmental meetings and lectures, visiting university research showcases, scanning faculty profiles, creating LibGuides about text mining, and participating in professional conferences. He also encouraged the audience to collaborate with data services and technical services colleagues.

Denise Novak (acquisitions librarian at Carnegie Mellon University) discussed text mining from the perspective of librarians in technical services. Text mining is an ongoing concern of 


\section{ACCEPTED MANUSCRIPT}

acquisitions staff because they are in regular communication with vendors about licensing and authorized forms of access. Additionally, at CMU (and perhaps other institutions) funding for datasets (the raw material for text mining) comes out of the regular acquisitions budget. Novak and other CMU librarians collaborate on a LibGuide that provides a list of free or licensed resources for text mining for CMU researchers. The Center for Research Libraries (CRL) and members of the LIBLICENSE listserv have crafted a model license agreement that includes support for text mining, and Novak regularly requests vendors to add support for text mining to their licenses.

Kristen Garlock (associate director of education and outreach for JSTOR) articulated a provider's perspective on text mining. JSTOR has welcomed text mining since the early 1990s as part of its ongoing mission to support new methods of scholarship. Text mining increases the visibility of publications in JSTOR, as the corpus comes to be seen as a valuable scholarly tool. Some text mining projects have provided valuable partnership opportunities, where JSTOR has been able to make available text mining research (such as new metrics) in ways that benefit all JSTOR users.

Currently JSTOR allows near-unmediated text mining through its Data for Research portal, which allows researchers to run keyword, n-gram, and other analyses on JSTOR journal articles, pamphlets, and associated metadata. Custom requests for larger result sets or complex analyses are also possible but require a letter agreement defining how the data will be used. JSTOR often fields text mining requests directly from individual researchers but can work with research groups or libraries. Garlock reported the volume of text mining requests is increasing, and more scholars are becoming interested in text mining (including some who may not be very familiar 


\section{ACCEPTED MANUSCRIPT}

with either the tools or dataset issues). Both of these trends present challenges for resource providers.

Patricia Cleary (global eproduct development manager for Springer Nature) rounded out the presentation by describing Springer's text and data mining (TDM) policy. As of June 2016, the gist of the policy is to grant mining access to subscribed content, provided the purpose is for noncommercial research. Researchers at institutions that subscribe to Springer Nature can download articles via SpringerLink; researchers or institutions who have not purchased subscriptions can request TDM access on a case-by-case basis. (Clery elaborated that Springer signs agreements with libraries, not individuals.) Springer supports automated downloading from SpringerLink, provides a metadata API for searching content, and is working with CrossRef on cross-publisher downloading. Content provided by Springer is digital rights management (DRM)-free content, so libraries can host it locally if needed, but querying SpringerLink will provide the most recent data.

Text mining presents new opportunities for researchers, but also new challenges for librarians and resource providers. The panel of speakers presented encouraging ways that librarians and resource providers could cooperate to make mining projects successful.

Remain in safe mode or embark on a new horizon?: A reconsideration of an academic library's current open URL link resolver service

Major tool upgrades are viewed by most technical services librarians with suspicion and dread. Although new tools promise greater efficiencies and additional features, they often bring headaches as well, from steep learning curves to tasks that suddenly become difficult or impossible in the new environment. Tales of woe abound at conferences, and many stay with 


\section{ACCEPTED MANUSCRIPT}

existing technology until external pressures force a change. However, sometimes upgrade stories have a positive ending. Rachel Erb (electronic resources librarian at Colorado State University (CSU) Libraries) shared her recent experience of planning for a link resolver upgrade. Although the migration ultimately did not take place, the planning and decision-making process provided valuable opportunities to rethink procedures and expectations.

Although CSU's existing setup worked well (involving SFX and EZProxy, as well as several local workflows), several factors prompted a review of the service. Gradual staff reductions in technical services made it increasingly necessary to automate routine tasks so that librarians and paraprofessionals could spend time on the more complex work of licensing, vendor communication, and troubleshooting. Shifting university priorities, such as a desire to share resources with libraries at branch campuses, provided an additional impetus to standardize procedures and reduce the amount of manual tweaking. Finally, the OpenURL (uniform resource locator) marketplace has significantly changed since the last technology upgrade, and it seemed a good time to see if other products could provide better value.

CSU's link resolver migration committee included a wide swath of staff from technical services, information technology (IT), public services, and administration. Some of the members remembered the implementation of the current technology, providing valuable historical experience.

The committee began by drawing up a list of ideal features in a link resolver, such as comprehensive coverage of electronic resources, MARC record service, ability to provide a "database of databases" in addition to a simple A-Z list, compatibility with other systems in use at CSU, a customizable user interface, good customer service, and a vendor commitment to 


\section{ACCEPTED MANUSCRIPT}

continued product development. The committee next used this feature list to develop a RFI (Request for Information) with 45 questions. Each committee member had responsibility for evaluating vendor responses to a subgroup of questions. After reviewing RFIs, CSU selected 3 vendors for trials and on-site presentations.

During vendor evaluations, the library found itself considering (and selecting) a full ILS replacement (Ex Libris's Alma), instead of just doing a link resolver upgrade. Although this turn of events was not completely unexpected - an ILS change had been pondered for several yearsthe vendor presentations led library administrators to broaden the scope of a possible upgrade, and served as a good reminder to the migration committee that system decisions are rarely made in isolation.

Currently the team is preparing for the ILS transition (named "Alma Mia!") by doing data cleanup and reading ILS documentation. Coordinating with a branch campus that is transitioning to the new ILS at the same time is prompting analysis of many workflows and procedures. Data migration, although done by the vendor, is requiring intensive customization to get existing data in a transferable format. Often several data sources have to be combined into one file for ingestion into the new system. Public launch of the new ILS is scheduled for January 2017. Lessons learned from this process included expecting the unexpected, and being flexible and nimble in planning for a system upgrade. Take a holistic approach to upgrading library services; do not make service decisions on the basis of a single tool. Even though drafting the RFI and analyzing responses was a lot of work, this knowledge is transferable and has proven useful in the upcoming ILS transition. 


\section{ACCEPTED MANUSCRIPT}

The ending of CSU's migration story is yet to be written, but Erb's presentation reminded the audience that such stories are not necessarily tragic — and that there is value in planning for upgrades even if they do not actually take place as expected.

ER sleuths are on the case: Best practices for e-resource acquisitions

"I can't get to my database!" echoed the cry through the conference hall. Troubleshooting electronic resource problems often require detective skills worthy of prime-time television. A Clue-inspired skit about eresource troubleshooting illustrated how seemingly simple problems often have complex solutions. Librarian V.I. Warshawski, Mrs. Peacock and Mrs. Green of Peacock Publishing, and Miss Scarlett, the subscription agent, all played a role in solving Professor Plum's database dilemma.

A robust troubleshooting workflow is an important tool for any eresource sleuth, reported Deberah England (electronic resources librarian at Wright State University). Public services staff triage eresource problems from patrons into three categories. "Basic" problems are handled directly by public services while "Complex" and "Critical" problems are referred to Wright State's eresources troubleshooting team (ERT) via a web form. (Critical problem reports are also accompanied by a phone call.) The ERT includes staff from multiple library departments allowing reported problems to be quickly assigned by functional specialty. The appropriate ERT member analyzes and corrects the problem, contacting vendors or third-party providers as necessary, and responds to the reporting staff member within 24 hours. Library administration has championed the use of the web form to report eresource problems rather than simply calling or emailing individual staff members, so problems can be quickly assigned to relevant ERT members and to ensure all relevant information is included in the report. 


\section{ACCEPTED MANUSCRIPT}

How can subscription agents assist in troubleshooting? Tina Feick (director of Sales and Marketing for Harrassowitz) stated that agents have a dream: "every library able to order an ejournal and get automatic access that is trouble free." However, communication gaps between publishers, agents, and libraries often prevent the dream from becoming reality. Subscription agents play an important role in troubleshooting by helping information flow freely between publishers and librarians. Feick strongly encouraged libraries to create (and keep current) an eresource profile that can be supplied to agents with contact information, FTE counts, Internet protocol (IP) ranges, consortia memberships, and other institutional data. When problems arise, many agents have reporting systems that allow subscription agents to assist in troubleshooting by providing payment information and other data needed by the publisher. However, Feick cautioned, tell your agent when access has been restored, because publishers will often communicate directly with librarians, leaving agents wondering if the problem is still outstanding. One future hope is automatic information exchanges between agent systems and publisher systems, reducing the time needed for updates to propagate from publisher to agent to library (and vice versa), and bringing everyone closer to the dream of automatic access. Susan Davis (acquisitions librarian for continuing resources at SUNY-Buffalo) emphasized the pivotal role of communication in eresources troubleshooting. Communication with patrons can help manage reasonable expectations about the time needed to order and activate a new resource. Internal communication with colleagues in collection development about new products can avoid awkward situations involving purchasing and licensing, and reduce wasteful duplication of effort. External communication with publishers and agents can facilitate quicker responses to problems. Davis also offered tips on "collecting clues" towards successful troubleshooting: did 


\section{ACCEPTED MANUSCRIPT}

you pay for the resource, and has the payment been received? Do the other actors, such as campus procurement and publishers, have the right institutional information on file? Has the platform URL changed? What browser and platform is the patron using? (Different browsers behave differently.) Once you have enough "clues," it is time to "make the case" to the resource provider or campus colleague who can fix the problem. Davis suggested explaining the problem clearly and respectfully, with relevant information and evidence such as screenshots, bearing in mind the recipient may not be a fellow eresource librarian.

In the end, Professor Plum's wail of despair resulted from a lack of (computer) communication: the publisher had recently changed their authentication policy, and the library's OpenURL resolver was not passing proxy credentials with every URL. Detective-librarian V.I. Warshawski identified the issue and solved the problem, with help from her subscription agent and publisher. Sharing best practices can help all of us successfully "close the case" when doing eresource troubleshooting.

\section{Laura Kohl}

Special Collections Cataloger, University of New Mexico, Albuquerque, NM 87131, USA; email:

\section{kohll@unm.edu}

Classifying librarians: Cataloger, taxonomist, metadatician?

David Nelson (chair, Collection Development \& Management) and Beverly Geckle (continuing resources librarian)--both of Middle Tennessee State University--presented on their findings aimed at shedding light on several new issues surrounding the changing nature of the role of the cataloger. After completing a thorough examination of all job advertisements referencing cataloging or metadata creation, which had been posted on the email listserv AutoCat from 2013- 


\section{ACCEPTED MANUSCRIPT}

2016, Nelson and Geckle explained that libraries are being forced to do more with less, and this reality is impacting the current nature of the jobs available within the library field. It would seem that many institutions are trying to do the impossible by hiring individuals with a background in both traditional librarianship and computer programing, a skill not traditionally taught in library school.

Nelson and Geckle began the session by explaining that technical services departments have always been plagued by high levels of attrition, something that has not changed in recent years. What appears to have changed is the rising demand for these departments to do more with diminished resources, and the emergence of the term 'metadata' in current library job ads has proven to be no exception. The term has remained elusive since its first use in early 2000 , even though it can now be found in job titles and under preferred and necessary skills required of new hires. Nelson and Geckle suggested that this points to a general oversimplification of the needs of these departments and the job responsibilities expected of individuals. Despite a proliferation of available jobs in technical services, the continued practice of merging the role of the cataloger and the metadata librarian into one single job continues to be problematic.

Geckle explained that the very size of the job advertisements themselves has increased in the last 50 years with those published in 1991 being a mere 150 words and those published in 2011 jumping to more than 500 words. The advertisements examined in the past three years can be divided into the following position categories: cataloger, metadata librarian, metadata librarian and cataloger, metadata librarian and other, and neither. The job titles themselves can be confusing. It appears that the role of cataloger places an emphasis on working with physical objects, while metadata librarians deal more with electronic resources. What was abundantly 


\section{ACCEPTED MANUSCRIPT}

clear from Nelson and Geckle's research was that libraries seem to need an abundance of skills and knowledge, and as the speakers best phrased it, libraries are requiring everything in new hires including 'metadata and the kitchen sink.'

Also discussed in the session are the fundamental differences in understanding regarding what metadata is and its usage; with catalogers viewing metadata as content in records and metadata librarians defining metadata as tags. This has led to a continued lack of clarity surrounding the roles that both of these positions perform. The absence of references to content standards in the job advertisements suggested greater issues related to the library catalog, such as deficient authority control, inconsistent headings, and a dearth of requirements in controlled vocabularies. All of these things point to an overall preference for keyword searching among the users of the catalog. In light of these discoveries, Nelson and Geckle would like to see the term metadata librarian be replaced with taxonomist.

Nelson and Geckle addressed some of the personal qualities libraries are seeking in new hires with one of the most common being someone who is 'innovative.' Once again, there seems to be little clarity on the part of libraries regarding whether they are seeking an innovative person or one that is comfortable with innovation. A dramatic increase in job responsibilities, with some of these responsibilities centering on the areas of computer programming and software, also suggests that libraries are struggling in their technical needs. This begs the question: are libraries requiring too much from potential job candidates for one person to handle? This seems to ring true, considering that most people seeking jobs in the library field have a library background and not one centered on information technology. With the many additional requirements placed on 


\section{ACCEPTED MANUSCRIPT}

library faculty, many of whom are under constant pressure to provide both public service and continuously publish, it seems that the role of the academic librarian has become unsustainable. The session rounded out with a lively discussion among the attendees of similar issues that they each face in their respective libraries. Many echoed the sentiment that they saw library faculty being continuously pushed into an impossible situation of publish or perish, which leaves very little time left over to train and mentor new individuals just entering the library. The question that seemed to be most prevalent was whether libraries should be willing to bring new hires in if they came with a broader background in areas such as information technology rather than continuing to require so many years of experience and formal training solely in the library field. There did not appear to be a clear consensus on this question among the group. A central theme throughout the entire presentation was that when libraries combine the role of the cataloger with that of the metadata librarian, there is a possibility of losing sight of the cataloger's primary mission, which is to properly classify materials.

Managing content in EBSCO Discovery Service: Action guide for surviving and thriving Regina Koury (assistant university librarian, Discovery \& Resource Services) and Charissa Brammer (electronic resources librarian), both of Idaho State University Library, discussed their experience managing content in EBSCO Discovery Service (EDS). Koury began the session by explaining that Idaho State University (ISU) is a Carnegie-classified doctoral research and teaching institution with over 14,000 students. In 2014 ISU completed a successful migration from Primo to EDS. Now users of their library catalog can conduct searches under the 'OneSearch' search box located on the home page of the library. Koury discussed how the 


\section{ACCEPTED MANUSCRIPT}

advanced OneSearch tab was highly utilized by the users, leading ISU to create a LibGuide describing the purpose and functionality of EDS.

ISU maintained two profiles for both the main library and the Idaho Health Science Library (IHSL). The two share a very similar profile, and both use Voyager as their integrated library system and EBSCO's Full Text Finder (FTF) for electronic and print materials. Koury also explained that a 'rebuild' of the catalog was necessary, resulting in suppressed items (those items that are withdrawn or lost) to be filtered out so as not to show to the users. New records are downloaded from the catalog to EDS on a daily basis.

According to Koury, the MARC21 record '856 links' for ISU's ebooks became an area of concern. Koury explained how she and her colleagues became aware of the concurrent user limit associated with these direct links to the ebooks. The limit on access was causing a problem with the end users, so at their request EBSCO removed the filtering to resolve the issue. Other points of concern had to do with ISU's government documents that were 'bound with' other documents causing much confusion because only the first title would appear in the search. There seems to have been no resolution with this particular issue. Koury explained that web widgets were also unable to search the EDS search interface, so a widget application was employed, particularly for International Pharmaceutical Abstracts (IPA). Around this time library staff became aware that ClinicalKey could not be searched through EDS leading EBSCO to create a widget application solely for ISU. By 2016 EBSCO was able to make ClinicalKey content searchable using EDS, thus removing the need for the widget. Koury further explained how Research Starters, Associated Press Videos, and other related images began to appear in the catalog after making the switch to EDS. After some debate among the staff of ISU, with many finding the additions 


\section{ACCEPTED MANUSCRIPT}

'not scholarly enough,' the content was removed by EBSCO. This solicited a collective groan from the audience to which Koury replied that she had been 'overruled' in this decision.

Koury recommended that those currently using EDS or those simply interested in the product subscribe to EBSCO Discovery Service Content Update Newsletter as well as the EDS Partners Listserv. The EBSCO Blog and EDS Wiki are other useful sources of information. Koury stated that Full Text Finder had been the easiest portion of the content to manage and that on the whole EBSCO had offered excellent customer service to ISU in assisting with their many questions and concerns.

Camelia Naranch

Stanford University Law School Library, Stanford, CA, 94305, USA; email: cnaranch@law.stanford.edu

Do serials have a place in the institutional repository?

Kay Teal (metadata librarian for serials and arts resources, Stanford University Libraries) was the sole presenter at this well-attended and highly informative NASIG 2016 conference session, held on June 10, 2016, in a meeting room of the Hotel Albuquerque. She argued convincingly, using ample evidence on her accompanying slides, that newsletters, newspapers, and magazines deserve to be included in online digital repositories. They do, however, present a different range of challenges than monographic resources, like books, dissertations, and book chapters. Teal's talk offered an introduction into the complexities of this issue, using hands-on examples drawn from her direct personal experience working closely with the Stanford Digital Repository (SDR) while a metadata librarian at Stanford University Libraries. She also included examples from other university libraries, including Harvard University and the University of Kansas. 


\section{ACCEPTED MANUSCRIPT}

As Teal explained, it was easier for librarians to put monographic materials in institutional repositories than serial resources. For this reason, many repositories appear to be lacking access to serial publications in their collections. Teal outlined the practical reasons for this apparent neglect, some of which relate to the cataloging challenges of creating appropriate Metadata Object Description Schema (MODS) records for multiple records or an ongoing publication series with print as well as digitally created content. Teal expressed optimism that the complex workflows and technical challenges connected to serial additions to institutional repositories should not dissuade metadata librarians and other serials specialists from forming task forces to confront the existing problems that currently limit the range of serials materials that are accessible. She concluded with a list of issues that are likely to be resolved by serials librarians in the future: avoiding the obvious pitfalls of record duplication, dealing effectively with incomplete runs and other problems associated with missing issues or incompletely digitized records, and finding discoverable ways for online users to search by title and keyword for serials records within an institutional repository platform.

In the lively question-and-answer period that followed, multiple audience members pressed Teal for additional information on the SDR platform and its compatibility with open access principles. She was also asked about the desirability of creating Persistent Uniform Resource Locators (PURLs) for each serials record, her experiences with various serials and university press publishers, the opinions of her colleagues when working with serials as compared to monographic titles, and the search options for records within a repository format. The discussion elicited a range of reactions from the audience, who were sympathetic to Teal's advocacy for serials inclusion in institutional repositories and approving of the work she and her Stanford 


\section{ACCEPTED MANUSCRIPT}

colleagues had already accomplished. However, they expressed a healthy skepticism that the process - as Teal rightly recognized - was far from complete, and that multiple technical and practical hurdles remained to be resolved in the future. Her presentation slides are available online at http://www.slideshare.net/NASIG/do-serials-have-a-place-in-the-institutional-digitalrepository.

Jharina Pascual

Electronic Resources Acquisitions Librarian, University of California Irvine; email: jharina@uci.edu

Charting a course toward embracing evolving technical services horizons

Nadine P. Ellero (head of Technical Services at Auburn University) provided an introspective summation of the massive transitions in staffing, skill sets, and workflows occurring within library technical services over the past few decades. Ellero's experience is particularly relevant as a librarian who assumed increasing responsibility over staff and departmental functions through major restructuring and hiring changes within Auburn.

That said, Ellero's underlying theme was the idea that technical services in libraries are always complex. Even as the Auburn University libraries are currently working through physical expansion, collection assessment, and moving items to off-site storage, Ellero's technical services team has always had to deal with various routine pressure points from within and from public services departments. There are, for example, the management of both the print and electronic workflows, the proliferation of data across various knowledgebases, and the increasing complexity of acquisitions models and workflows. The consistent turnover of standards and technology has required that staff develop new skills consistently. This is an issue when 


\section{ACCEPTED MANUSCRIPT}

technical services managers are often dealing with unit members who are risk averse and afraid of failure.

Of course, this is all driven by the need to constantly improve the efficiency and accuracy of library services. Libraries have had to manage the expectations of faculty and students as well as the limitations of products and pricing from vendors. These tensions become especially apparent now that libraries are set to implement another significant transition in standards - linked data that has significant implications not only for back-end technology and workflows, but also resource discovery. Ellero presents a diagnosis via an article by Peter Davis (1980) in the Journal of Library Administration: "as the environment of user needs becomes less stable, more heterogeneous, and less predictable ... The number of exceptions begins to far exceed the number of routine transactions."

Ellero notes that this was written in 1980, and yet technical services librarians will consistently write (and speak) about their internal processes as if the complexity is a new and surprising phenomenon. Key to navigating the complexity is a technical services manager's willingness to prepare their staff for ongoing changes through multi-faceted training plans that take advantage of staff members' core strengths, all while maintaining positive attitudes and resiliency through difficult work transitions.

Managers must first focus on the people themselves. Staff require the appropriate amount of training and time to adjust to new tasks. Managers should also pay attention and adjust to the differing training needs of newer staff members versus long-time staff and help them to feel comfortable with change. Per Ellero, managers would do well to adopt a servant leadership model of supervision, in which they see themselves as supporters of staff through major changes 


\section{ACCEPTED MANUSCRIPT}

and set the tone for accomplishing major projects. In this role, a manager can promote values of respect, teamwork, and lifelong learning. A manager can also adjust training to acknowledge the specific work styles of their department and provide a safe environment for the employee to give and receive critical feedback.

Crucial to these adjustments, of course, are the specific unit and departmental goals that must be clarified beforehand. Defining these goals can help identify relevant staff strengths, possible incentives for making adjustments, and the specific skill sets necessary to acquire or strengthen. The pitfalls of such an intensive process include manager/leader burn-out, which highlights the need for self-care. However, there could be effects on staff wherein disagreements over new policy or individual mistakes could direct the unit or department into any of what Ellero highlights as the five dysfunctions of a team: absence of trust, fear of conflict, lack of commitment, avoidance of accountability, and inattention to results (Lencioni, 2000). Taking a holistic approach to major structural changes, however, carries the potential for a unit and a department to become a better team. It helps to build confidence, resiliency, and better interpersonal relationships. It also creates a culture where mutual trust and respect, acts of listening and reflection, and tangible support from supervisors and co-workers cultivates an environment in which staff feel the freedom to share ideas and try new things without feeling threatened by change.

References

Davis, P. (1980). Libraries at the turning point: issues in proactive planning. Journal of Library Administration, 1, 20-21. 


\section{ACCEPTED MANUSCRIPT}

Ellero, N. (2016). Charting a course toward embracing evolving technical services horizons [PowerPoint slides].

Lencioni, Patrick. (2002). The five dysfunctions of a team. San Francisco: Jossey-Bass.

The Canadian Linked Data Initiative: Charting a path to a linked data future

True to NASIG 2016 theme of "Embracing New Horizons," the presentation of the Canadian Linked Data Initiative by Marlene van Ballegooie (University of Toronto), Juliya Borie (University of Toronto), and Andrew Senior (McGill University) provided an edifying summation of the larger structural changes as well as the internal project management that may be mandated by a large-scale implementation of linked data.

The project was spurred in part by the increasing salience of linked data projects in major research libraries around the world, such as the Linked Data For Production (LD4P) Project (Linked Data for Libraries, 2016) and BIBFLOW (UC Davis Libraries, 2016), both of which seek to transition aspects of technical services data and workflows into linked open data. The Library of Congress also signaled the eventual transition away from Anglo-American Cataloguing Rules, Second Edition (AACR2) and MARC by introducing the BIBFRAME (Bibliographic Framework) initiative in 2011, which would standardize descriptive metadata into linked data.

However, the critical spark for the Canadian Linked Data Initiative occurred in 2015 at ALA's Technical Services Directors of Large Research Libraries Interest Group meeting (otherwise known as Big Heads), wherein the heads of three Canadian ARL libraries felt that they contributed little to a conversation about linked data initiatives. The 2015 Access Conference (Canada's major library technology conference) was the site of a series of meetings in which the 


\section{ACCEPTED MANUSCRIPT}

heads of the top five Canadian research libraries invited various linked data experts to speak about their projects (Access Conference, 2016).

From this convention, the group of libraries agreed to collaborate on a project that would incorporate aspects of linked data production from training to editing. They agreed to formalize communication between the different university institutions, as well as invite Library and Archives Canada, the Bibliotheque et Archives Nationales du Quebec, and Canadiana.org into the partnership. This partnership would increase the pool of available resources and take advantage of the strengths of the various institutions.

Major aspects of the project would be subdivided into various working groups, with a coordinating group overseeing the entire project. The Steering and Planning Group, for example, would provide an overarching vision and leadership for the project, as well as guidance on policy issues; they would also take charge of the documentation. The Education and Training Group would gather critical resources, communicate information, and conduct training and assessment for the participants of the linked data initiative.

The Education and Training Group are especially crucial to the Canadian Linked Data Initiative because they act as a clearinghouse for resources not only for the theory and implementation of linked data, but also the core competencies and pedagogical tools required for staff involved in implementation. One of the future goals of this group is to compile a set of best practices for implementation and content for online learning modules.

Other notable groups include the Digital Projects Group, which gathers materials for a multiinstitutional digital repository - possibly one that is focused on Canada's 150th anniversary. The Groupe de travail Francophone is tasked specifically with French-language documentation and 


\section{ACCEPTED MANUSCRIPT}

metadata. The Identifiers group is tasked with all matters related to metadata standards, from dealing with legacy metadata to integrating recommendations from the Program for Cooperative Cataloging on Unique Resource Identifiers in MARC. So far, the group has dealt extensively with enhancing records with persistent identifiers and enriched subject facets. Of course, there is also a Grants group, working on accumulating funds for the project.

Finally, the BIBFRAME group experimented with the functions of Library of Congress' BIBFRAME editor. They tested the ability to access non-English language records, the input and output, the customizability of the interface, and the skill sets that would be required to produce bibliographic records using the editor.

While this is an impressive start for a multi-institutional initiative that is only about a year old, the presenters outlined major issues that could affect the project long-term. The distance between the partner institutions is a major obstacle to collaboration, as are the multitude of languages and institutional practices contained therein. Funding is a consistent problem, especially considering that the project has been introduced in a context where staff time and resources are already scarce. Finally, conceptual and workflow changes implied by the transition to linked data necessitates massive changes in libraries' infrastructure and training models, which will take time to plan and execute.

Nevertheless, Ballegooie, Borie, and Senior predict that the partnership between the various institutions will create opportunities for staff and librarians to pool knowledge and address ongoing problems collectively. The Canadian Linked Data Initiative hopes to improve coordination between various library work units and vendors with regards to systems migrations and digital repositories. They will also continue to contribute to a more widespread development 


\section{ACCEPTED MANUSCRIPT}

and dissemination of linked data in library systems in order to enrich discovery. Finally, they hope to increase Canadian institutions' collective incentive to continue researching and educating each other on developments in the world of linked data and beyond.

References

Access Conference. (2016). Home page. Retrieved from http://accessconference.ca/

Ballegooie, M., Borie, J., \& Senior A. (2016). The Canadian linked data initiative: charting a path to a linked data future [PowerPoint slides]. Retrieved from http://www.slideshare.net/NASIG/the-canadian-linked-data-initiative-charting-a-path-to-alinked-data-future

Linked Data for Libraries. (2016). Home page. Retrieved from https://www.ld4l.org/ University of California Davis. (2016). BIBFLOW Project. Retrieved from http://www.lib.ucdavis.edu/bibflow/

Martin Patrick

Electronic resources and media cataloger, St. Olaf and Carleton Colleges, Northfield, MN, 55057,USA; email: patric1@stolaf.edu

Open access in the world of scholarly journals: Creation and discovery

Chris Bulock (electronic resources librarian at California State University Northridge) and Sandra Cowan (liaison librarian for English, Modern Languages, Religious Studies and the Faculty of Fine Arts at the University of Lethbridge in Alberta, Canada) shared their experience and thoughts on open access publishing by and for libraries. They also discussed solutions implemented locally and globally, along with the technical and philosophical obstacles that must be overcome before open access can achieve its full potential. Starting with the well-known 


\section{ACCEPTED MANUSCRIPT}

serials crisis and the various responses possible to it, Bulock and Cowan presented open access as a sustainable solution for both libraries and the research community. Cowan talked about initiatives at her institution and library, including a journal incubator to promote and publish open access scholarly content. She explained the differences between green and gold open access. Bulock discussed the technical hurdles that interfere with providing reliable access to open access content and pointed to a new National Information Standards Organization (NISO) best practice as a potential solution once it is correctly implemented by content and discovery vendors.

Libraries have long been aware that the costs of journal subscriptions are increasing beyond the ability of libraries to pay. A study by Larivière, Haustein, and Mongeon (2015) in Canada found that journal costs had increased over 400\% from 1986-2013--more than four times the rate of inflation--while mergers and acquisitions have led to a situation where more than $50 \%$ of journal articles were published under the umbrellas of just 5 publishers. Publishers have also begun to exert more control over content through other acquisitions, like Elsevier's purchase of Mendeley, the free reference manager, and the Social Science Research Network (SSRN). Cowan believes it is only a matter of time before Elsevier attempts to monetize these, which will have a deleterious effect on the open access (OA) world.

Cowan suggests that open access is the long-term, sustainable solution to the serials crisis and that libraries should play a key role in the creation of both OA content and the OA movement. There are several kinds of open access publishing available, with differences in how the costs of production are recovered by the publisher. The two main branches are called "green" and "gold" open access. Green open access is not necessarily published, rather it is best described as "self- 


\section{ACCEPTED MANUSCRIPT}

archiving." In green OA, the researcher deposits the article into a repository of some kind, such as an institutional repository hosted locally, or a depository such as arxiv.org which hosts content from researchers all over the world in specific subjects. Green OA does require coordination with the publisher of the final content of the article, but the access to the article is made available independently of the publisher.

In gold OA, the costs of publication come into play and are paid for in one of two ways. In "true" gold OA the journal content is freely available and there is no subscription fee required to access it. These journals are supported by author processing charges (APCs) or some other mechanism. In hybrid gold OA, the journal requires a subscription and fee, but also requires some authors to pay APCs. The hybrid model is a great deal for publishers, according to Cowan, because not only have the costs of these journals generally not decreased, they are now getting some APCs on top of it. While hybrid OA does contribute to more content being available, it has an enormous benefit of money and power for the publisher.

Cowan favors true gold OA, as this directly inhibits the power of publishers over libraries. Content is published, and the cost of publishing is spread out among the researchers who publish it rather than being passed on to the library or other organization who subscribes to it. While APCs can be problematic for researchers, there is increasing support provided to researchers who are often able to bundle the APCs into the grant proposal or who have access to money from their institution. Another factor in favor of true gold OA is that many grant-making bodies or tax supported projects require research generated to be published in true open access journals. Other common obstacles to publishing in true gold OA journals are more abstract. Cowan discussed the common perceptions that OA journals are predatory--that is, that OA journals 


\section{ACCEPTED MANUSCRIPT}

charge the author for publishing but provide no added value such as editorial or peer-review services. The lack of peer-review is another common misperception about OA. Broadly, the current journal system has developed to support the tenure and promotion system used in higher education. As a result, publishing in certain journals is essentially required, which has created a powerful inertia for researchers to publish only in these journals, many of which are not open access. Finally, while libraries are at the forefront of advocating for OA, libraries often do not have much institutional authority and are unable to direct researchers towards OA through OA policies.

Even this is changing, however. Cowan notes that many schools, such as Concordia University (Montreal), now have mandatory OA publishing policies for all staff and faculty. As already noted, many research support institutions require the research generated to be published in open access journals. At Cowan's institution, the University of Lethbridge, the library has undertaken a series of projects and collaborations aimed at promoting OA publishing and increasing the library's institutional authority to drive change.

There are technical obstacles to widespread OA adoption as well, particularly in regards to hybrid OA content. Bulock showed a scenario in which a particular article is open access in a journal that is not, on the whole, open access. He also demonstrated the resulting inability of the discovery system to point the user to the content. This is because, according to Bulock, discovery systems work at the institutional level and can really only resolve to the issue level. This creates a frustrating experience for users, as once they have reached the point of discovering they do not have access it is sometimes difficult to back up and request via interlibrary loan (ILL). For now, Bulock advised that it is best for libraries to take advantage of multiple layers of access, through 


\section{ACCEPTED MANUSCRIPT}

the library discovery service and the web, using services like Google Scholar or LibX, a browser plugin to help discover resources.

Lethbridge's library offers copyright and licensing consulting to researchers to help them better understand the terms of publishing, their intellectual property rights, and more. The University has also started a Centre for the Study of Scholarly Communications, of which the library is a key partner, which exists to advocate for and educate about scholarly communications issues, including open access publishing. At Lethbridge, researchers who have received grants work with the Office of Research and Innovation Services. Cowan reports that the library has worked with staff there to encourage researchers to explore OA publishing options. Another large initiative is a journal incubator that now publishes three gold OA journals for scholarly societies. Lethbridge serves as a model for how libraries can approach advocating for OA publishing. Cowan suggests that libraries should advocate, help researchers find money to pay APCs, and lead by example. Libraries should also invest in local repositories, external repositories, and services like the Directory of Open Access Journals (DOAJ), the Directory of Open Access Repositories (openDOAR), as well as projects like the Open Library of Humanities (OLH). And

most importantly, as Larivière has done, do the research and show the benefits of OA publishing not just to the researchers but to the academy at large and society.

Bulock reported on a NISO project called the Access and License Indicators. Formerly it was referred to as the Open Access Metadata Initiative. This seeks to provide structure for content providers to indicate that a journal article is open access or otherwise freely available so that a discovery system can report that to the user. However, this relies on both discovery and content providers, including institutional repositories, to implement the indicators correctly. Currently, it 


\section{ACCEPTED MANUSCRIPT}

is not well implemented by either side of the discovery equation, but Bulock stresses the need for libraries to advocate for this feature.

\section{References}

Larivière, V., Haustein, S., \& Mongeon, P. (2015). The oligopoly of academic publishers in the digital era. PLOS ONE, 10(6), e0127502. doi:10.1371/journal.pone.0127502

Shaping expectations: Defining and refining the role of technical service in new resource rollouts Jeffrey Mortimore (discovery services and data curation librarian) and Debra Skinner (interim head of Collection and Resources Services), both of Georgia Southern University, explored the role that technical services staff should play in communicating to internal and external library users when new eresources have been acquired or when current eresources have received a substantial platform or content update. Mortimer and Skinner grounded their approach to developing a resource rollout protocol using Oliver Pesch's "E-resource life cycle" chart, as seen and discussed in many presentations and papers, and the idea that to library patrons, library service is service, regardless of whether it is public or technical service staff providing it. The impetus for this protocol included past experiences with resource confusion and an opportunity presented by the departure of the head of technical services at Georgia Southern. The technical services (TS) department petitioned the library's administration to create a new position to manage TS communications more effectively, rather than to immediately try to fill the vacant department head position. Jeffrey Mortimore was hired into this position, coming from a strong background in public service and instruction. The department thus began to seek 


\section{ACCEPTED MANUSCRIPT}

effective and efficient ways to communicate about eresources. They developed a protocol and template that could be applied to all resource rollouts going forward.

In the past, Georgia Southern had inconsistent messaging about eresources, resulting in not just a lack of awareness but also confusion surrounding how to use these new materials. Mortimore and Skinner reason that technical services are the "first owner" of new resources, as TS is usually responsible for acquisitions, activations, and metadata. They even faced a situation beyond their control that brought this into focus. A consortium of which they are a member decided to turn on WorldCat Discovery without notification, and Georgia Southern's library found out through a professor's angry Facebook post. The protocol has been developed to minimize this risk.

Another guiding principle behind Georgia Southern's protocol is that, to library users, service is service. They do not distinguish between technical and public services. Only librarians do internally, and the internal distinctions can cause confusion to external users. Therefore, as the group of people most familiar with the new or updated resource, technical services staff represents the most knowledgeable choice to provide information to the library's community of users.

Because technical services serve as the "first user" of a resource and the staff responsible for ongoing technical support for the resource, TS staff are in the best position to become the first and best experts. Because of this, TS staff should be the ones communicating with all users about a new resource, according to Mortimore and Skinner. TS staff coordinate configuration and testing using a go-live timeline they have developed, which should lead to a better user 


\section{ACCEPTED MANUSCRIPT}

experience. The protocol developed, however, also allows public services staff to experiment and test.

Library resource rollouts require communications to two sets of users. The first group--and the first group to receive messaging under their protocol--are departmental liaison librarians. The messaging developed for the internal communications includes information about the content, the expected public go-live date, and a link to a frequently asked questions (FAQ) page, hosted through LibAnswers, to help librarians become exposed to and familiar with the new resource, which is already active and live in the catalog and the A-to-Z list. The second group of users to receive messaging are the external library users--faculty, staff, and students of the university-which is sent out on or just after the date chosen as the public go-live date.

The protocol is designed to ensure that the resource is well-understood by library staff before rolling out to the public. Guidelines divide tasks into two categories: implementation tasks and communication tasks.

[insert Figure 3 here]

Thus the protocol covers not just communication but the whole process of rolling out a new resource. It creates a consistent environment for testing by public services staff to become familiar with the resource and a consistent message to convey key information to users. One concept supporting this is that the resource has "gone live" before "go live." In other words, the resource is actually active and available before official communication that it is available. The go-live announcement is sent out twice: at two weeks before and at one week before. After the go-live date, a series of public release communications formally alerts the end user that the resource is available. 


\section{ACCEPTED MANUSCRIPT}

While they have been pleased so far with response to the rollout protocol and communications developed, there is no formal mechanism to measure, compare, and analyze the feedback received. Another lingering issue to be explored and incorporated into the protocol is resource "rollbacks." Electronic resources do not always just rollout, sometimes they are cancelled or suffer from some other loss of access. As of the presentation, they do not have anything set up to deal with this situation, but it is a priority to develop.

Emily Ray

Metadata and Discovery Services Librarian, University of Arkansas at Little Rock, Little Rock AR, 72204,USA; email:ejray@ualr.edu

How many libraries do we need?

James J. O'Donnell (university librarian at Arizona State University (ASU)) presented the third and final vision session, "How many libraries do we need?" In this wide ranging talk, he touched on such topics as high tech libraries, customer service, on-campus physical collections (where libraries traditionally direct their labor), and his vision for the future. O'Donnell began by stipulating that his talk will "treat as inevitable, things you think are crazy and idealistic." $\mathrm{He}$ also referenced the previous presentation he had heard and stated that he was "horrified by the petty things that are necessary to provide access" to electronic resources. For the first section of his talk, O'Donnell showed a slide of the opening of the Princeton Fireman library in 1948 and imagined it as "high tech and modern" for its time. He also talked about a documentary of the French National Library in 1956 showing its high tech features of pneumatic tubes. O’Donnell presented these as examples that "we've always lived in a high tech world" and that high tech of each era provided discovery and access to patrons. 


\section{ACCEPTED MANUSCRIPT}

ASU is currently moving its physical collections off site, leaving 250,000 to 500,000 volumes in the library on campus. O'Donnell envisioned a physical collection that will not just be decoration. He suggests cycling the collection, compared to a static core collection, by having books on Italy for 6 months, paired with lectures on events and on Italian culture. The next cycle could be books on Darwin with the intent that the collection will be a "showplace, a showroom for the library" to "dazzle" and interest students in new topics.

O'Donnell next addressed customer service, displaying the not-so-friendly paper slip on an ILL book: "Renewals are not permissible \$ nonrenewable fee. Keep this strap ON to avoid penalty." The purpose of the paper strap is to track an interlibrary loan book. Could this be done another way? Would tracking the lending institutions' call number in ILLiad serve that function without the unfriendly label? O'Donnell asked if there is a way to get the data we need for services, without so much labor invested in "OCD labelling." O'Donnell connected this process to the larger question of how many copies of titles we (communally) need.

In the next section, O'Donnell changed gears and referenced Ted Leavitt's Marketing myopia. He made the analogy that railroads did not understand the industry they were in, leading to a decline in the middle of the $20^{\text {th }}$ century, suggesting that libraries might be in a similar situation. So what business are libraries in - information storage and retrieval, discovery, inquiry, entrepreneurship? Being the place to go when you are not sure where to go or what to do? Libraries should think about the future activities for focus and energy versus the type of content currently receiving the bulk of librarians' labor.

Returning to his original question, "how many libraries do we need," the answer, according to ALA's website, is 119,000, which would make 1 out of 3,000 Americans a library director. With 


\section{ACCEPTED MANUSCRIPT}

a global population of 9 billion, we would need 3 million libraries for the world, but should be considering the activities that would best support those libraries, and move away from "obsessive detailing for electronic resources" by each library. We should be imagining a single library, where every human being can access information for questions that matter to them. O'Donnell described consortial electronic resources as a "stunning success" for libraries, although there are lots of local details and big deal type issues.

O'Donnell was asked about marketing for libraries, which he acknowledged is "not a strength for some of us." He suggested librarian subject specialists work with instructional designers, not just on LibGuides, but in designing courses and assignments as librarians. He also advocated focusing on the building design of the library. Libraries should "dazzle the eye and catch their attention" when students come in to do homework.

The second question asked was: "Why is using ebooks such an awful experience?" O’Donnell agreed and described ebooks as better for discovery, but worse for actual use. He suggested that if print on demand became cheap enough, perhaps that could become the solution.

When there is no magic bullet: An interlocking approach of managing ebooks

Xiayon Song (electronic resources librarian at North Carolina State University Libraries) began her talk, "When there is no magic bullet: An interlocking approach of managing ebooks," by describing her institution's libraries. NCSU collections include 5 million volumes, 550,000 ebooks, and have a \$10 million collections budget. Song's department, Acquisitions and Discovery (A\&D), has 25 full-time positions across three units, Monographs, Serials, and Data Projects and Partnerships. 


\section{ACCEPTED MANUSCRIPT}

Upon introducing her library, she next described a Lego workshop led by a visiting librarian to inspire creative thinking, learning, and problem solving. Together with a box of Legos, Song and others considered the tasks they do as librarians and represented that work through Legos. In her case, she expressed ebook management as constructing a Lego building and matching up needs with systems through connecting Lego pieces. Missing Lego pieces represented needs not met. After the Lego metaphor, Song outlined the processes and resources NCSU uses to manage ebooks, including their use of CORAL (an open source electronic resources management system) and in-house development of an ebook title reconciliation workflow. NCSU acquires ebooks through individual firm order, demand driven acquisitions, a North Carolina library consortium (NCLIVE), and as ebook packages and collections, with 77 packages purchased in fiscal year 2014. NCSU employs the Serials Solution knowledgebase, a Sirsi Dynix ILS, and the Endeca discovery layer. In their workflow, MARC records are loaded into their ILS. They store ebook package licensing data in the E-matrix electronic resource management system (an inhouse ERM predominately for serials data), using such fields as: vendor, tax identification number, agreement, status, related resources, organizational contact, and roles. For individual monographic titles, collection management initiates the purchase request and sends it to a specialist, the specialist distributes to staff, and staff members place the orders in GOBI (Yankee Book Peddler's book ordering database Global Online Bibliographic Information) or with other book vendors. Staff members later pay the invoice. Due to the volume of requests and the need to confirm that requests are ordered, NCSU requires a tool to manage this process and make the path and status of individual requests transparent. 


\section{ACCEPTED MANUSCRIPT}

NCSU often purchases ebook packages at the end of the fiscal year with end-of-year money. Collection management approves the request, then librarians encumber money in the ILS, negotiate the license, and request the invoice. Once the invoice is paid, a librarian sets up access to the ebook package.

As with individual monographic titles, library staff want the status of packages clear to stakeholders. With both individual titles and packages, there have been problems with access. These problems happen due to a variety of factors: it is unclear which database to activate, it is difficult to find the database in the Serials Solutions knowledgebase, it is unclear which titles have been purchased, or staff cannot obtain a certified list of titles from a vendor.

To address these issues, NCSU looked at CORAL, an open source electronic resource management software starting in 2013. CORAL was first envisioned to provide workflow support for monographs. NCSU incorporated support for CORAL into their existing electronic resources management committee in December 2013; this group examined CORAL and turned requests over to their Information Technology (IT) department in May 2015. IT made some changes, and A\&D staff began using CORAL for new orders starting in November 2015. With this workflow, staff would create the resource in CORAL, encumber the money in the ILS, document the license, request the invoice, pay the invoice, check access, activate the database, and document the steps taken. Within CORAL, a staff person can see what is in their queue. However, they do not receive reminders of work that needs to be completed. NCSU received a grant to address that missing function, which is currently under development. It is also possible to delete a step in the workflow in CORAL, if the step is not necessary for that resource. NCSU expanded their eresource hub (a wiki made in Confluence) already used for e-journals to include 


\section{ACCEPTED MANUSCRIPT}

ebook package administration. This space is used to maintain collection-related information such as publisher lists of titles, quick links, and lists of reconciled titles. There is an ebook package profile template that tracks the fund used, a link to the license in E-matrix, the purchase

order number in the ILS, and other activities (such as whether a resource is approved for purchase in the next fiscal year or just one year).

All of this information supports ebook reconciliation in a Microsoft Access database. The Data Projects and Partnership unit built an ebook record title database in Microsoft Access, where monographs unit staff run queries looking for mismatches--such as no MARC record, no rights listed, titles not listed in their ILS, or titles not active in their Serial Solutions knowledgebase. Once the queries identify a small number of mismatches, staff members investigate and resolve the issue. This is less work than examining each title in an ebook package for 77 ebook collections.

For her final recommendations, Song suggested examining your existing system in terms of what it can and cannot do, and focusing on the needs not met. Once the unmet needs are identified, explore other solutions to address them.

In answer to questions, Song stated that NCSU does plan to share the ebook reconciliation database with other libraries. It is a Microsoft Access database, and they can share the queries used and the structure of the tool.

\section{ALA Annual Conference \& Exhibition}

Kristin Rogers, contributor

Electronic Resources \& Discovery Librarian, University of Mississippi, University, MS, 38677, USA; email: kerogers@olemiss.edu 


\section{ACCEPTED MANUSCRIPT}

ALCTS Scholarly Communications Interest Group: Finding meaning in metrics

Scholarly communication librarians' relationship with research impact metrics

Over the past five years, the way that academia views metrics such as impact factors (IF) has

broadened to include other measures like altmetrics. Rachel Miles (digital scholarship librarian, Kansas State University Libraries) defines altmetrics as the volume and nature of attention that research receives online. Altmetrics includes social media sites such as Twitter, Facebook, blogs, and citation managers like Mendeley.

Miles distributed a survey to over 13,000 librarians asking how altmetrics was being used in jobrelated tasks and professional development. Out of the librarians who received the survey, 707 responses were returned, or 5.3\%. Survey results showed that the biggest reason that librarians use altmetrics is to evaluate journal quality. Among tenured librarians, citation counts are used most, and altmetrics are used the least. A large percentage of those surveyed said that they intended to include altmetrics in their tenure dossier, but the percentage of librarians who actually did was much lower. Out of all librarians surveyed, $32 \%$ said that they do not track metrics at all.

Measuring towards openness: Using alternative frameworks and metrics to better assess and discover researchers and their contributions

Robin Champieux (scholarly communications librarian, Oregon Health and Science University Library) studied journal impact factors to evaluate the contribution of research and quality of available metrics. The median for the IF list was 1.341 , the mean was 2.00 , and the average was 1.415. The recently released 2015 Impact Factor list showed that almost 12,000 journals had an 


\section{ACCEPTED MANUSCRIPT}

IF of less than zero. With so many journals having such a low impact factor, academics began to explore alternate ways to evaluate research.

IF and other traditional metrics do not necessarily represent the quality, influence, and contribution of research and researchers. Altmetrics allow for an openness of measuring research by examining how information is being used. Researchers can see how their information is being discovered, where it is being accessed, and much more. It may take years for traditional impact methods to show how a paper or piece of research is used. With altmetrics, academics are able to evaluate research through the amount of times an article is blogged, tweeted, or saved in a citation finder such as Mendeley or Zotero. Evaluating research in non-traditional ways provides a greater view of the impact of a researcher's contributions to academia.

Why we need to think about new metrics for research evaluation in the age of social media Ehsan Mohammadi ( $\mathrm{PhD}$, Northwestern University, post-doctoral research fellow, Department of Preventative Medicine-Health and Biomedical Informatics) began his presentation by explaining how San Francisco's Declaration on Research Assessment (DORA) does not endorse citation-based metrics like the journal impact factors. DORA was signed by 12,697 individuals and 622 scientific organizations. The reasons for this declaration are that citations are limited to authors' perspectives, need 3 to 5 years for accumulation, and are more appropriate for theoretical publications. These thoughts have prompted researchers to explore new types of metrics. The National Science Foundation takes other formats beyond print into account. The National Institutes of Health uses biosketch format for a more diverse impact factor, and the Higher Education Funding Council for England includes research done outside of standard academia. 


\section{ACCEPTED MANUSCRIPT}

As scholarly communication changes, so do the ways impact factors are evaluated. Scholarly communication is becoming a more open and diverse culture of sharing, linked data, and enhanced publication. Mohammadi explained how altmetrics aims to find complementary measures for traditional metrics based on scholars' activities on social web platforms. There are a number of organizations who are examining alternative metrics as a solution. The Becker Model for Assessing Research Impact, Academic Careers Understood through Measurement and Norms (ACUMEN), Research Excellence Framework (REF) Impact Case Studies, and Canadian Academy of Health Science (CAHS) Framework are four possible frameworks for solutions. A study was done too see if there were any correlations between altmetrics and citations. The citation manager Mendeley's readership counts had the highest correlation between altmetics and citations. It was also found that readership counts could show "invisible research impacts" such as educational and practical impacts.

Mohammadi concluded by stating that the National Information Standard Organization (NISO) is currently researching altmetric standards. As researchers, funders, and publishers begin to increase their use of altmetrics, more research is needed to fully understand how alternative metrics work.

Electronic Resources Management Interest Group: Making it count: Usage statistics and electronic resources management

Collecting usage statistics brings about a number of challenges for librarians. Two of these challenges are quantity and quality. The number of resources and platforms that one must access to gather statistics is high. Vendors do not all use the same reporting standards, providing various 


\section{ACCEPTED MANUSCRIPT}

types of reports. Due to the large quantity of reports, libraries need to have enough staff to not only gather statistics, but to compile the information in a useful way.

There are significant differences between how vendors report their usage statistics. Many vendors are COUNTER 4 compliant, but some still supply non-compliant statistics. Librarians are faced with determining what non-compliant statistics mean and how to compare them to other statistics. Some vendors claim they are compliant when they are not.

In determining which parts of the available information to share, one must consider the audience who will see and evaluate the statistics. Librarians and staff usually prefer to have the entire statistical raw data. Administrators and patrons prefer to see trends shown on a graph, rather than spreadsheets of raw data.

Jennifer Bazeley (interim head of Technical Services, Miami University) uses free and low cost tools to consolidate and present usage statistics to Miami University. Miami Libraries use Google Spreadsheets (part of Google Drive) to load, compile, and share usage statistics within their organization. Library staff download usage data monthly from each provider and copy the data into the appropriate Google Spreadsheet. Some staff members have the ability to edit these spreadsheets while others can just view.

Miami’s Technical Services department manages and maintains a LibGuide for usage statistics. The LibGuide is used to share statistics and includes general information about COUNTER standards. Reports on ebooks, evideos, databases, and ejournals are available to view in their LibGuide.

In addition to the free and low cost tools, there are vendors who offer commercial products to help collect usage statistics. For example, EBSCO has the products Usage Consolidation and 


\section{ACCEPTED MANUSCRIPT}

EBSCONet. Usage Consolidation allows for an automated gathering of statistics using Standardized Usage Statistics Harvesting Initiative (SUSHI) protocol. This service produces consolidated data across platforms and shows any "lost" data by estimating what that might be. Using SUSHI, statistics directly from the vendor can be loaded into EBSCONet to generate usage statistics and cost per use reports.

Jill Emery (collection development librarian, Portland State University) serves on the Executive Committee of Project COUNTER. Emery stated that usage reporting is contextual. When gathering usage statistics, one must first be aware that different audiences require different data. Understanding not only the level of data sought but also the desired outcome saves time when gathering usage. It is important to be as concise as possible when presenting usage statistics and data to make them easily understood. Customizing both the level of data and the amount of information shown for different audiences helps vested parties find the information they desire. There are many resources available to assist with any questions and issues one has about running and compiling statistics, which include: the updated Project COUNTER website; Lib-Stats discussion list; electronic resources in libraries (ERIL) discussion list; friendly guides with hints and tips from pages such as USUS, a community website on usage named for the Latin word for usage (http://www.usus.org.uk/).

The method in which statistics are gathered can vary depending on the library. Statistics can be gathered using SUSHI protocol or by manually downloading COUNTER compliant statistics. Non-compliant statistics must be handled one by one since the usage reports are unique to the individual resource. Usage statistics can be run in many different ways. A library may choose to gather statistics yearly, monthly, bi-yearly, based on the fiscal year, or any other way depending 


\section{ACCEPTED MANUSCRIPT}

on type of statistic available. Emery's library chose to supply usage and cost per use data over a 3 to 5 year time span to account for resources used during classes that are not taught every year. Oliver Pesch (chief product strategist, EBSCO Information Services) serves on the Project COUNTER Executive Committee and the COUNTER Board of Directors. He described COUNTER as “a Code of Practice seeking 'consistent, credible \& comparable' usage reporting for scholarly online information." Vendors who use COUNTER determine what reports to provide, the format and metrics in the reports, how to process transactions logs, and how the reports are to be delivered. The five main types of COUNTER reports are journal reports, database reports, book reports, media reports, and platform reports.

In 2013, the COUNTER 4 update was released. There were four main features of this update: sessions were removed, federated and automated searches were added, results "clicks" and record views were added, and SUSHI was required. The COUNTER-SUSHI Implementation Profile was released in 2012 to coincide with the release of COUNTER 4. This profile provided a clearer understanding of the protocol and provided aids for SUSHI server developers. Between February 2015 and February 2016 the number of platforms that successfully used SUSHI went from a $40 \%$ success rate to a $95 \%$ success rate. USUS is a community website for COUNTER users to discuss any issues that arise. USUS also includes links to useful resources.

In 2015, NISO released SUSHI-Lite. This allowed for the embedding of COUNTER statistics in other applications. An example of this is in EBSCONet renewals. Usage is shown to help libraries determine how much a title is being used and to make decisions about renewals. There are a number of things that are in the works for COUNTER. COUNTER has a new, more user friendly website with a fresh look which provides a lot of information for users. A 


\section{ACCEPTED MANUSCRIPT}

COUNTER report validator is being developed which will do three things: allow vendors to validate their own COUNTER reports prior to being audited, reduce the cost and time required for audits, and allow librarians to validate their own reports and report any errors. This validator is being funded by the EBSCO Foundation.

COUNTER Release 5 is in development, with goals to provide more clarity with a comprehensive glossary, descriptions of how reports and metrics are used, and scenarios.

Release 5 will also deliver more consistency between reports and include more general reports. COUNTER will be formalizing a plan for future enhancements and aspires to allow for changes without waiting for the full release to be available.

References

Miles, R. (2016, August 2). Scholarly communications librarians' relationship with research impact metrics [PowerPoint slides]. Received via email.

Muhammadi, E. (2016, June 25). Why we need to think about new metrics for research evaluation in the age of social media [PowerPoint slides]. Received via email.

Breanna Webb

E-resources Management Librarian, Southern Methodist University, Dallas, Texas; email: bdwebb@smu.edu

Library Workflow Exchange: Sharing the "how" of what we do

During the Continuing Resources Acquisitions Forum, Anna Neatrour (University of Utah) and Liz Woolcott (Utah State University) introduced Library Workflow Exchange (LWE). The prototype was developed in June 2015 with a soft launch in October 2015. In less than a year, the site has yielded over 5,600 sessions, over 4,000 users, and more than 12,000 page views. 


\section{ACCEPTED MANUSCRIPT}

Including Woolcott and Neatrour, there are currently four editors, with hopes of adding more by the end of the year, especially Tech Services folks. As everyone's organizational structures determine how their workflows go, it is up to the user to ascertain whether a workflow posted on the site works for them. There are no set criteria when it comes to uploading workflows. Any file format that is linkable on the web, such as a multi-page Word document, or even a link to a YouTube video, are accepted. When a workflow is uploaded, it remains intact; nothing is amended by the editors. There are mainly links out to the documents on existing websites, but items located on a staff intranet may be physically placed on LWE. There is currently a plug-in on the site that takes snapshots of the links as a sort of backup, just in case some of the workflows become unavailable. LWE is less an archive and more an index and place to search for ideas. You can get involved by submitting your own workflows or pointing to someone else's, becoming an editor and/or using and sharing the site.

Re-tooling acquisitions for lean times

John Ballestro (Texas A\&M University) shared the "LEAN principles" he learned through the re-tooling of his department. Efficiency continues to be vital with budgets and staffing levels decreasing. More is needed with less funding, people, and experience across all types of libraries. The goal is to create a perfect value through the perfect process with zero waste. As a baseline in the acquisitions department at Texas A\&M, they wanted to quantify how long it took for a physical item to get from the box to the shelf. They discovered they were getting about $75 \%$ of items onto the shelf within one work week (five days). With the use of an outside consultant, a 95/5 goal was set, getting 95\% out in five days. 


\section{ACCEPTED MANUSCRIPT}

The downside of working with an outside party was the additional time it took to explain to the consultant things that someone working in acquisitions would already know. It also involved lengthy explanations about the various functions in the department. The department ultimately investigated ways to reduce the physical travel of an item, re-distributing work across other areas to maximize peak and valley workloads, reducing redundancy, and redesigning units for better collaboration. As a result, they have created a more open floor concept for the copy cataloging and receiving areas of the department, collapsed unused spaces which are flexible enough to move around if needed, and are continually striving to be closer to the $95 / 5$ goal.

Through the re-tooling at Wake Forest, Jeff Eller (Wake Forest University) emphasized crosstraining and efficiencies. Every process has been taught to multiple people, and while there is no formal process in place, they have annual goals to learn how to back up different processes. It results in a more flexible department that can absorb additional work when needed to cover things like parental leave, attrition, or extended sick leave. They have seen a tendency towards symmetry in the overall department, which seems to help when shifting duties from one to another. Eller made a note to not overly cross-train; there is a limit. If a team member is never actually called upon to do a task that is taught, where is the value? Efficiencies achieved included leveraging space, leveraging history and context, and vendor consolidation. Very little movement is wasted, with materials coming in and being processed at one end of the room. The manager is in the middle of the people who report to him so that he is more aware of what is going on. They were able to move people from one position to another, essentially giving those affected full knowledge of two jobs in the department. This helped with communication of value to the administration of the library. By consolidating vendors, they simplified workflows and 


\section{ACCEPTED MANUSCRIPT}

minimized training time, especially with student workers, not having to train them on two separate workflows.

The presenters made several suggestions, including asking more of your vendor's customer service, especially with help managing a DDA program. Vendors are happy to help, particularly when they are getting more business. Embrace the consolidation. Not everything worked out perfectly, and there are a few ongoing issues. Procedural documentation has fallen off the radar. When multiple people can perform a particular task/job and each of them can move around, documentation may become a lower priority, when it actually becomes even more important. Workload gravitation has been observed, where people are taking on more than they can handle, or miscellaneous tasks are going to the people quickest to take them on. There is also a reliance on student workers, and while there are sometimes a few excellent ones, that is not always the case.

Let's play family feud: A public services/technical services dialogue Rebecca Kemp Goldfinger (University of Maryland), Steven Shadle (University of Washington), Rachel Minkin (Michigan State University Libraries), Lynn Jacobson (Jacksonville Public Library), and Lizzie Gall (Grand Rapids Public Library) participated in this forum.

An informal survey was sent out to various email lists regarding continuing resources and communication, in which responders were asked to identify themselves as 'public services,' 'technical services,' or 'other,' and over 500 responses were received. Using three questions from the survey, two members from the audience--one a public services librarian and the other a technical services librarian--joined a panelist at the front of the room to play three rounds of "Family Feud." After the three rounds, the moderator and panel discussed themes in 


\section{ACCEPTED MANUSCRIPT}

communication challenges between public and technical services. Notable takeaways included patrons having difficulties with 'continuing resource' lingo. One panelist said, "Catalogers should step out of their box and recognize the fact that public services and the public users do not always recognize the lingo.” A few common complaints about continuing resources mentioned in the survey proportionately higher by the 'public services' and 'other' category were embargoes, lack of availability online, and 'where is the full text.' Other communication topics were discussed, and one audience member said that everyone at her institution participates in job shadowing monthly, where they are required to do a shift in a different department once a year (4 hours for part-time employees and 8 hours for full-time employees).

Mentoring demystified: Partners in success

Kathryn Deiss (Kathryn Deiss Consulting), Janice Flug (American University Library), Regina Gong (Lansing Community College), Heylicken Moreno (University of Houston Libraries), Sarah A. Norris (University of Central Florida), and Deborah Tenofsky (University of Cincinnati Libraries) participated in this session, which discussed the two mentoring programs. One is now available through LLAMA (Library Leadership \& Management Assoc.), and one will begin through ALCTS (Association for Library Collections \& Technical Services). This session explained that a pair of people could be co-mentors; it does not have to always be a one-to-one mentor/mentee relationship. Additionally, self-reflection needs to take place when applying to be a mentor or mentee. One presenter stated: "Exploring backgrounds and differences helps create a respectful and honest relationship." By knowing yourself and getting to know the other person, a more balanced, effective relationship can potentially form. Keep in mind that all pairings do not work out, and we should normalize the ability to exit, not condemn it. It should also be noted that 


\section{ACCEPTED MANUSCRIPT}

mentoring relationships do not always have to be geographically close; virtual mentoring is an option. In this instance, both the mentor and mentee need to pay close attention to expressed needs. According to Deiss, $70 \%$ of communication is nonverbal, so that is lost when virtually communicating. Mentors and mentees need to establish a frequent conversation schedule, at least monthly. There is a difference between a sporadic relationship with contact every six to eight months and one with a consistent line of communication. When things get cancelled, re-schedule them immediately. Combine communication methods and connect in person whenever possible.

\section{IFLA World Library and Information Congress}

Anjana H. Bhatt, contributor

E-resources Librarian, Florida Gulf Coast University (FGCU), Fort Myers, FL, 33965, USA;

email:abhatt@fgcu.edu

The IFLA 82nd World Library and Information Congress was held August 13-19, 2016, in Columbus, Ohio.

Open access collections: Current scenario in American academic libraries and a sample work flow

Anjana Bhatt (e-resources librarian, Florida Gulf Coast University (FGCU)) has established fulltext access to more than 90 open access (OA) collections at FGCU library. She tracks these OA collections via the Serials Solutions knowledgebase, which results in providing access to these collections via an ejournal portal and Serials Solutions MARC records. In her view, OA resources are increasingly becoming very popular among the information seekers, library professionals, and publishers. She briefly described the nature of OA collections and provided statistics regarding the dynamic growth of freely available Internet-based collections from 


\section{ACCEPTED MANUSCRIPT}

several publishers such as PubMed Central, Highwire Free, Directory of Open Access Journals (DOAJ), Directory of Open Access Books (DOAB), Internet Archives, Science, Technology, Engineering and Mathematics (STEM) Archives, Research Papers in Economics, Social Science Research Network, Registry of Open Access Repository Mandates and Policies (ROARMAP), and Electronic Journals Library.

Anjana conducted an OA survey consisting of five questions posted to the ERIL listserv. The main purpose of the survey was to determine whether academic libraries in the United States have developed OA collection development policies or have a collection development team in place for the selection of OA resources. Other survey questions included the process of deciding access points, assigning specific employees for troubleshooting, and collecting any useful data to justify the time spent on troubleshooting OA resources. She received feedback from six librarians; the survey results indicated that very few libraries have collection development policies or any team in place. Libraries reported preferences for several options such as A to Z lists, LibGuides, MARC records, and ejournal portals for providing access to OA collections. None of the libraries listed troubleshooting OA collections as a priority. An electronic resources librarian is mainly responsible for troubleshooting. None of the libraries collected any data on the time spent for troubleshooting OA resources, because this is rolled into regular troubleshooting activities. Almost all of the survey respondents observed that $\mathrm{A}$ to $\mathrm{Z}$ or database locator pages are not preferred points of access for OA collections and that it is not a good practice to provide access to free and paid subscriptions from one location.

Attendees learned about OA collection policies, maintaining and troubleshooting issues faced by other university libraries, and several helpful ideas about selecting the best access points for OA 


\section{ACCEPTED MANUSCRIPT}

collections. Bhatt's presentation included a SWOT (strengths, weaknesses, opportunities, and threats) analysis of OA collections management process and a step-by-step workflow that can be modified and adopted by any library. The presentation ended with the provision of a bibliography and several hyperlinks to useful documents:

- ERIL Survey Results: https://docs.google.com/spreadsheets/d/1ruOkLTFGCVWoVobJj8nnCrgSqoj2Yu9yQd0IZWe158/edit?usp=sharing

- OA process at FGCU library: https://drive.google.com/file/d/0B07rAFSoeIbISIBXN0Y5WFQwb1U/view?usp=sharing

- List of open access collections: https://docs.google.com/spreadsheets/d/11ty8gJ1gm0o92BQ6gnnZ0UpSwi5-G9L01_pQYS3VDE/edit?usp=sharing

- Copy of the presentation: https://drive.google.com/file/d/0B07rAFSoeIbIdnBQN1BGTm92N0U/view?usp=sharing

Questionable practices in scholarly publishing: The stance of the ISSN Network Gaëlle Béquet (director, ISSN International Centre, France) discussed how the ISSN Network actively supports OA scholarly journals and repositories by disseminating free information about these resources on its web platform ROAD: Directory of Open Access Scholarly Resources (http://road.issn.org/). ROAD, established in 2012, provides the bibliographic and geographical metadata supplied by the ISSN network and contains 257 academic repositories, 145 conference proceedings, 14,633 journals, 231 monographic series, and 709 scholarly blogs. The OA publishing movement has grown significantly, but it is marred by several questionable practices favoring profit-generating activities over the advancement of sciences. Béquet provided 


\section{ACCEPTED MANUSCRIPT}

interesting OA growth statistics and described a scenario where OA journals are being published worldwide and new journals are being launched every week. She explained why it can be a real challenge to find current guidance for finding reliable journals. She further informed attendees that since 2012, the ISSN network has received ISSN requests lacking correct and verifiable information needed for unambiguous identification of the publication.

Béquet briefly discussed the "Think. Check. Submit" (TCS) campaign that alerts young and experienced researchers alike by helping them easily identify trusted journals and assess the credentials of a publisher. She stressed the importance of these guidelines, which exist to handle erroneous requests received by the ISSN network. Béquet urged attendees to think carefully before submitting a paper to any journal and to check to see if it really suits their work or in fact is a trusted journal.

Béquet's paper is available at: http://library.ifla.org/1462/1/114-bequet-en.pdf.

Revising the ISSN: Involving stakeholders to adapt a bibliographic standard to its ever-changing environment

Clément Oury (Data, Network and Standards Department, ISSN International Centre, France) provided a detailed background on the history of the ISSN standard and where it stands today. He discussed the need for revising ISSN standards and future steps that must be considered before the revision. He briefly touched upon the process of assigning an ISSN number and explained how publishers, libraries, service providers, and digitization agencies use the ISSN for managing their content and work processes. ISSN was established in 1975 with the International Standards Organization Technical Committee (ISO/TC) 46 (information and documentation) and S69 (identification and description). Since then, it has undergone four revisions, with the latest 


\section{ACCEPTED MANUSCRIPT}

having occurred in 2007 for the purpose of clarifying its scope and in the creation of the ISSN-L, or linking ISSN.

In April 2016, the ISSN International Centre launched a call for a systemic revision of the ISSN standard, and the organization was to complete a voting process during April to September of 2016. If the results are positive, then the organization will begin a systematic revision process that could take anywhere from 24 to 48 months. This revision is necessary to address the evolution of publishing models, the emergence of new concepts and description standards in library and publishing domains, the appearance of new identifiers, and the development of linked data. Oury urged the attendees and interested members of publishing industries and libraries to participate by contacting their ISO national body and assist in establishing a working group to undertake this challenging assignment.

Oury's paper is available at:

https://drive.google.com/file/d/0B07rAFSoeIbIYTFqUW1qaG4yTHM/view?usp=sharing Managing the transitional impact of open access journals.

Gayle R.Y.C. Chan (University of Hong Kong Libraries) and Allan C.S. Cheung (Department of Chemistry, University of Hong Kong) examined the current OA landscape, international trends, and academic concerns in the OA publishing industry. Further, they highlighted several concerns--such as copyright for OA articles being held by the publishers and not the writers--and observed that much of the research conducted by publicly funded money ends up being published in high priced journals to which libraries and public patrons ultimately have no access. Chan and Cheung discussed OA growth statistics in general and in particular at the University of Hong Kong (HKU). A study conducted at HKU indicated that during the period of 2006 to 2015, 


\section{ACCEPTED MANUSCRIPT}

OA publishing grew by a cumulative increase of nearly $500 \%$. Study results indicated that OA papers in the Health Sciences rose from 11\% to $26 \%$ and Life Sciences from 1\% to $27 \%$ in this period, whereas OA paper submissions in the Physical Sciences and Social Sciences increased slightly from $2 \%$ to $5 \%$ and $1 \%$ to $3 \%$, respectively. Future plans for their study include analyzing the data on actual article submission trends at HKU and gathering researchers' attitudes within the context of the university's OA policy.

The presenters ended by discussing the details about a recent agreement that has been put in place among several publishers, HKU libraries, and the Office of Knowledge Exchangehttp:/hub.hku.hk/local/oa.jsp--that allow HKU authors to publish in OA journals, in some cases for free or at a discount.

Their paper is available at:

https://drive.google.com/file/d/0B07rAFSoeIbIc0ZFZXlvSE9RWVE/view?usp=sharing Stockholm University Press-for researchers, by researchers-but what does the library publisher add?

Birgitta Hellmark (Stockholm University Library, Sweden) mentioned at the outset that her copresenter, Sofie Wennström, could not be present at the program and that she would be presenting alone. Hellmark works as deputy library director and is also chair of the Stockholm University Press Publishing Committee. Hellmark described in detail the threefold publishing support at Stockholm University Library, which includes supporting candidates with their dissertations, reviewing publishing opportunities for internally reviewed manuscripts and publishing externally reviewed books and articles via Stockholm University Press. Her presentation, however, was focused solely on Stockholm University Press activities, which has 


\section{ACCEPTED MANUSCRIPT}

published six books, is working with eight manuscripts to be published soon, and has six proposals under review. They are publishing five journals and the press offers EPUB (ebook file format) and PDF (portable document format) for free.

Hellmark also described the structure of the press and the role of its editorial board, researchers, librarians, and editorial working groups. She further informed the audience that their platform is designed to assist researchers and take care of the practical part of OA publishing. Most importantly, their policy allows copyright to stay with the author. The management team of the Stockholm University Press is able to take advantage of the university's network and market publications from an institutional and nonprofit point of view. Hellmark ended her presentation by mentioning important lessons learned, such as keeping in mind the purpose of scholarly communications in the public domain, using the marketing potential of $\mathrm{OA}$, and rethinking traditional marketing strategies by not wasting money on traditional book launches. 


\section{ACCEPTED MANUSCRIPT}

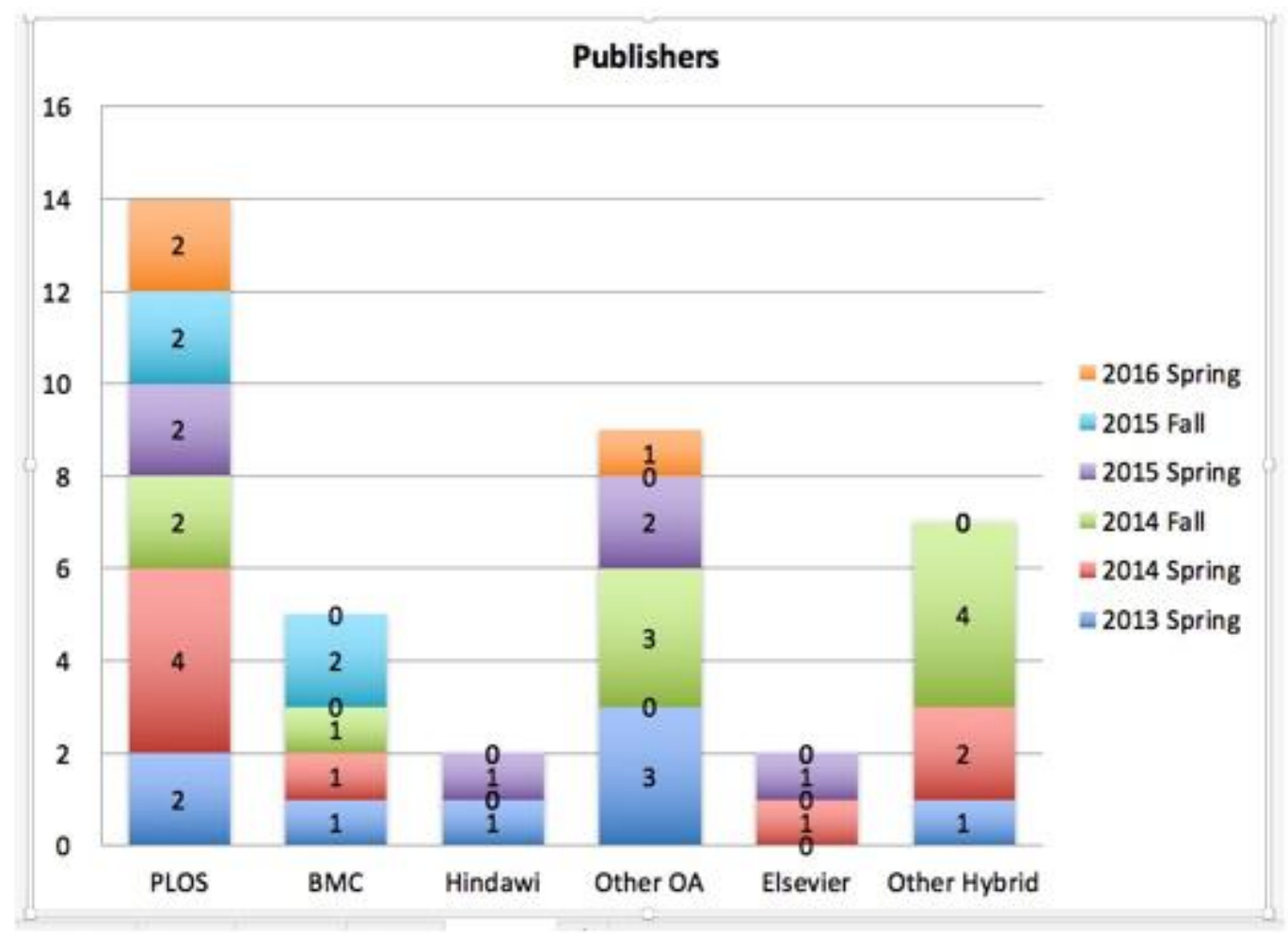

Figure 1. Awardees by Publisher. 


\section{ACCEPTED MANUSCRIPT}

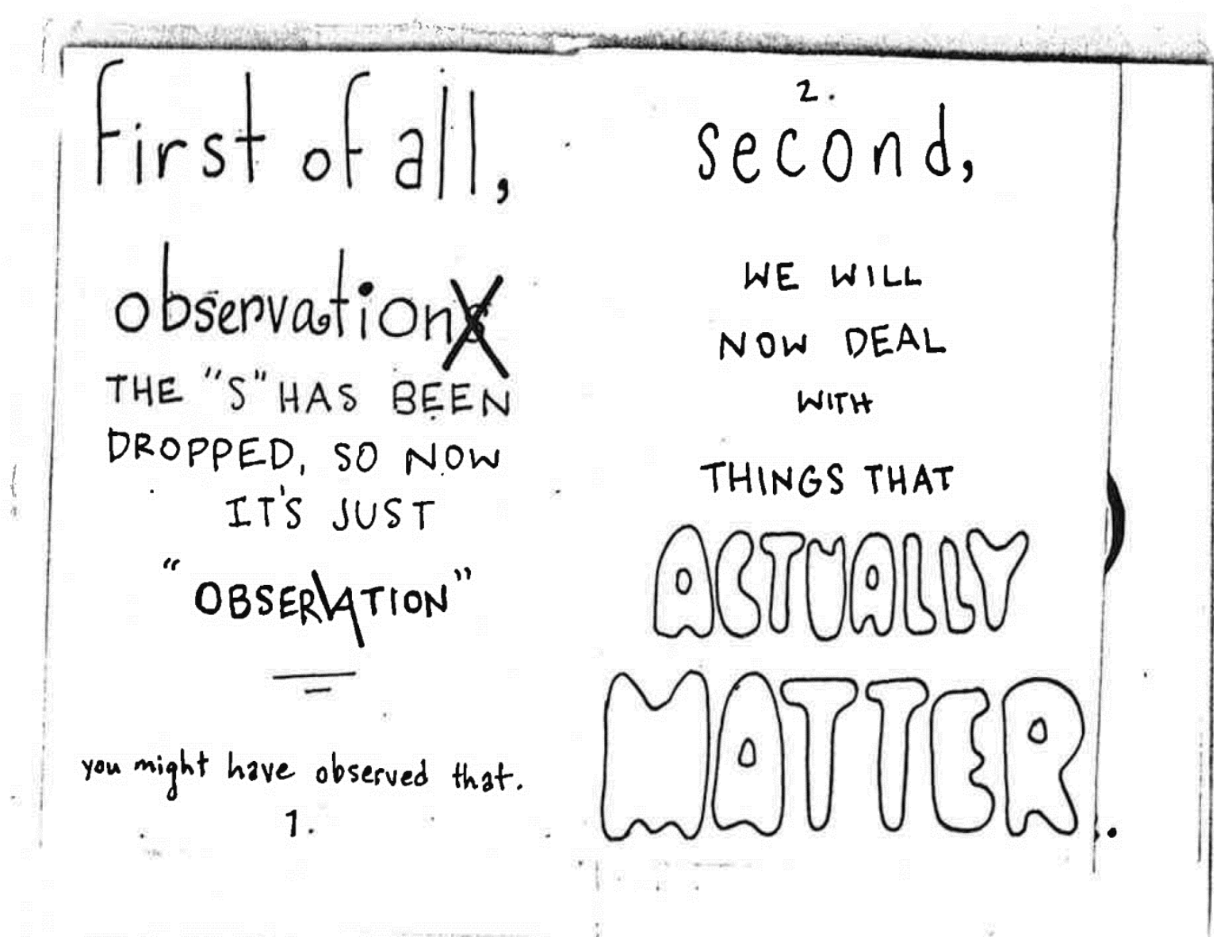

Figure 2. First page of the zine Observation, previously titled Observations. 


\section{ACCEPTED MANUSCRIPT}

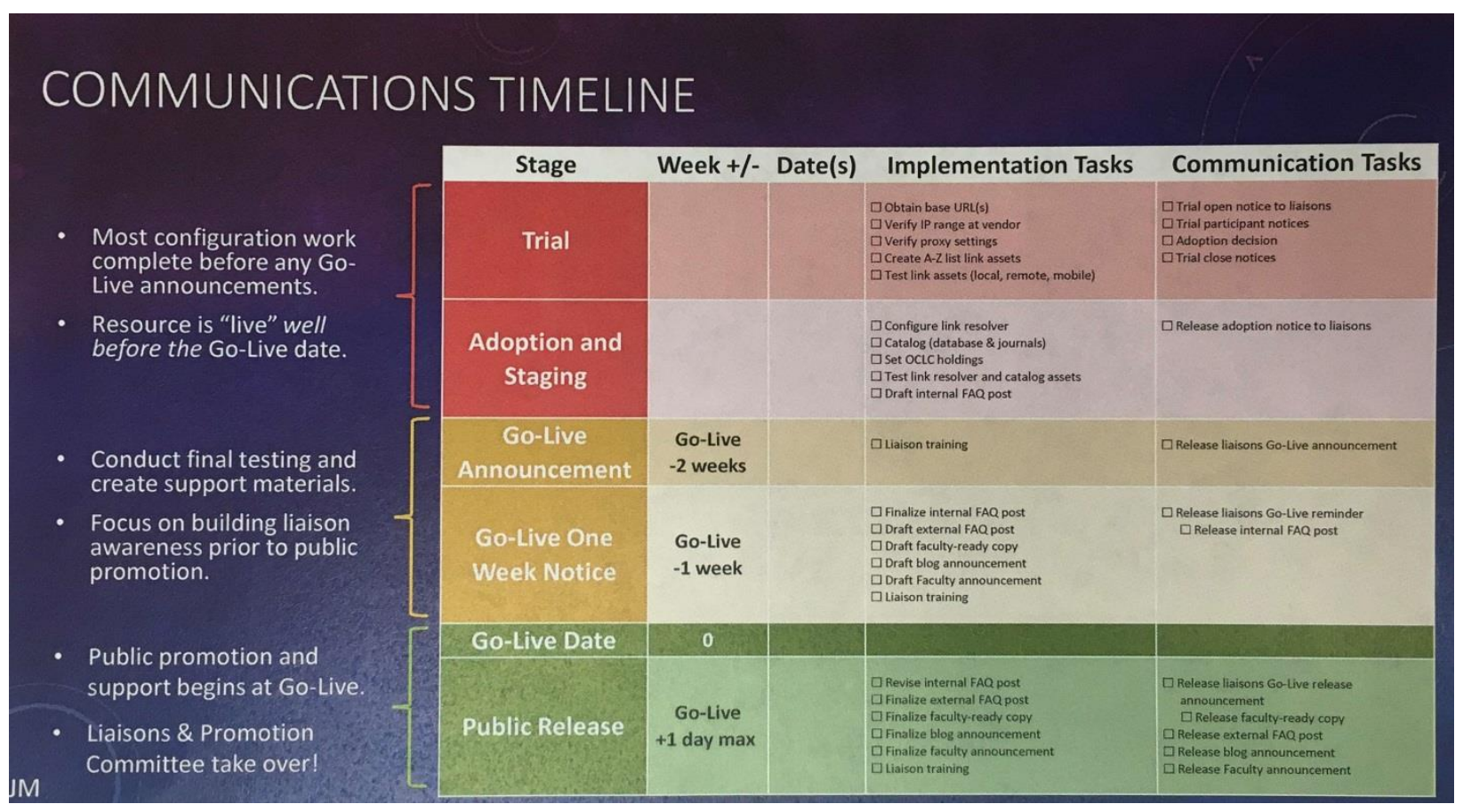

Figure 3. Communications timeline. 